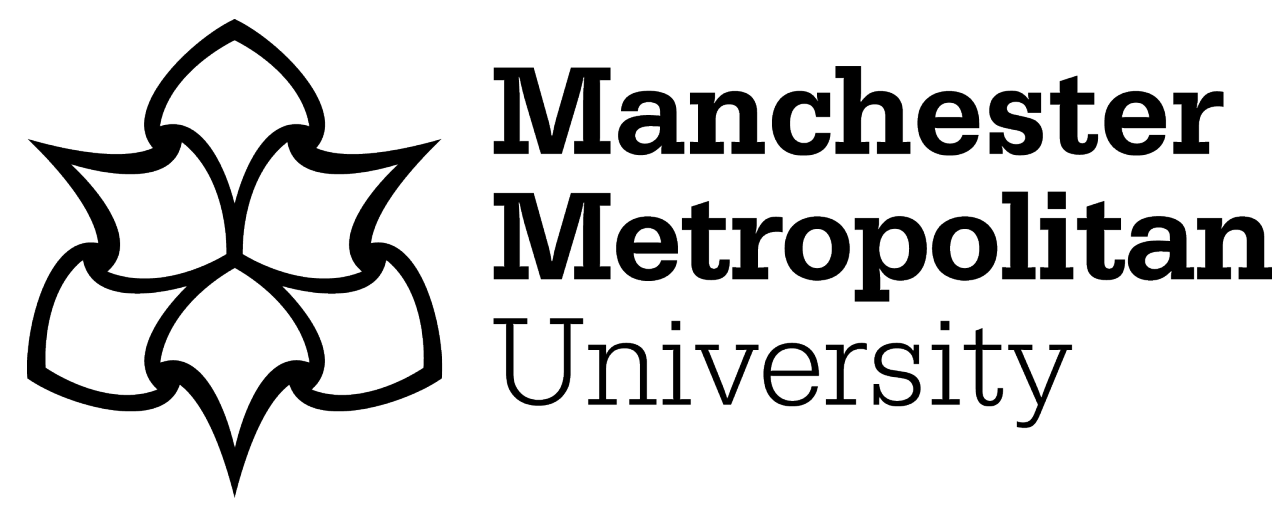

Junaid, M, Baig, MN, Shamir, M, Khan, FN, Rehman, K and Haider, J (2017) A comparative study of pulsed laser and pulsed TIG welding of Ti-5Al-2.5Sn titanium alloy sheet. Journal of Materials Processing Technology, 242. pp. 24-38. ISSN 0924-0136

Downloaded from: https://e-space.mmu.ac.uk/621337/

Version: Accepted Version

Publisher: Elsevier

DOI: https://doi.org/10.1016/j.jmatprotec.2016.11.018

Usage rights: Creative Commons: Attribution-Noncommercial-No Derivative Works 4.0

Please cite the published version 


\title{
A comparative study of pulsed laser and pulsed TIG welding of Ti-5Al-2.5Sn titanium alloy sheet
}

\author{
M. Junaid ${ }^{a}$, M.N. Baig ${ }^{b, *}$, M. Shamir ${ }^{c}$, F.N. Khan ${ }^{\mathrm{d}}$, K. Rehman ${ }^{\mathrm{a}}$, J. Haider ${ }^{\mathrm{e}}$ \\ a Faculty of Mechanical Engineering, GIK Institute of Engineering Sciences and Technology, Topi, KPK, Pakistan \\ b Pakistan Welding Institute, PO Box 1781, Islamabad, Pakistan \\ ' School of Chemical and Materials Engineering, National University of Science and Technology, H-12, Islamabad, Pakistan \\ d Faculty of Materials Science and Engineering, GIK Institute of Engineering Sciences and Technology, Topi, KPK, Pakistan \\ e School of Engineering, Manchester Metropolitan University, Manchester, M1 5GD, UK
}

Article history:

Received 18 June 2016

Received in revised form 23 October 2016

Accepted 16 November 2016

Available online 17 November 2016

Keywords:

Titanium alloy

Pulsed laser welding

Pulsed TIG welding

Residual stresses

Hole-drill method

Deformation

\section{A B S T R A C T}

Pulsed Nd:YAG laser beam welding (P-LBW) and pulsed tungsten inert gas (P-TIG) welding were used to prepare full penetration bead-on-plate weldments of $1.6 \mathrm{~mm}$ thick Ti-5Al-2.5Sn alpha titanium alloy sheet. The influence of welding phenomenon on the microstructure, micro-hardness, tensile properties, surface and sub-surface residual stress distribution and deformation and distortion of both the weldments were studied. Higher cooling rate in P-LBW resulted in complete $\alpha$ ' martensitic transformation in fusion zone whereas in P-TIG weldment $\alpha$ ' and acicular $\alpha$ was formed within equiaxed $\beta$ matrix due to lower cooling rate. Hardness in fusion zone of P-LBW was higher than that of the fusion zone of P-TIG weldment due to faster cooling rate in P-LBW. The welded zone in both the weldments showed higher hardness and strength than that of the parent metal since a ductile fracture occurred in the un-welded section during tensile testing. Residual stresses in both P-LBW and P-TIG weldments showed similar trend but the distribution was much narrower in P-LBW due to less width of heat affected zone. P-LBW resulted in more nonuniformity in through thickness stress profile because of greater top to bottom width ratio. Less residual stresses, deformation and distortion and superior mechanical properties in P-LBW made the process more feasible than P-TIG for the welding of Ti-5Al-2.5Sn alloy sheet.

\section{Introduction}

Tungsten Inert Gas (TIG) welding is a widely used process for joining titanium alloys due to reduced capital cost, simple and portable equipment with ease of automation. Lathabai et al. (2001) suggested that in addition to the conventional mode of TIG welding, it can also be performed on titanium alloys in the keyhole mode for higher productivity. Short (2009) found that because of reduced power density in TIG welding as compared to laser beam welding (LBW) and electron beam welding (EBW), relatively higher overall heat input was required to achieve full penetration which resulted in a wider heat affected zone (HAZ) and higher residual stresses and distortions. Gao et al. (2013) found that for welding thin sheets of titanium alloys, TIG welding led to high residual distortions and a

\footnotetext{
* Corresponding author.

E-mail addresses: massab@giki.edu.pk (M. Junaid), mnbaig8167@gmail.com (M.N. Baig), shamirtahir@gmail.com (M. Shamir),fahdnawaz@gmail.com (F.N. Khan), khalid.rehman@giki.edu.pk (K. Rehman), j.haider@mmu.ac.uk (J. Haider).
}

coarse microstructure. Balasubramanian et al. (2011) reported that TIG welding of Ti-6Al-4V alloy plate resulted in the highest impact strength as compared to LBW and EBW.

$\mathrm{Nd}$ :YAG pulsed laser beam welding is an advanced joining process in which melting and solidification of the weld zone takes place after each pulse by a more dense heat source. Ghaini et al. (2007) found Nd:YAG laser beam welding to be more efficient and controllable than TIG welding since the desired welding mode can be chosen by optimizing the welding parameters (pulse energy, shape, duration, speed and repetition rate). Squillace et al. (2012) investigated the conduction and keyhole regime based on heat input range of Nd:YAG laser beam welding and concluded that weld morphology was highly dependent on welding regime. The work done by Blackburn et al. (2010) and Gao et al. (2013) suggested that as compared to continuous laser beam welding, pulsed Nd:YAG laser beam welding produced less porosity in thin titanium alloy sheets due to its shorter solidification time. Akman et al. (2009) concluded that depth of penetration and weld bead geometry in LBW was controlled by the laser output parameters. They also reported that micro-hardness of weld zone was also dependent on peak 


\begin{tabular}{ll}
\multicolumn{2}{l}{ Nomenclature } \\
P-TIG & Pulsed tungsten inert gas welding \\
P-LBW & Pulsed laser beam welding \\
BoP & Bead-on-plate \\
FZ & Fusion zone \\
PM & Parent metal \\
HAZ & Heat affected zone \\
$\alpha$ & Alpha phase \\
$\alpha^{\prime}$ & Alpha martensite \\
$\beta$ & Beta phase \\
$\varepsilon$ & Strain (mm/mm) \\
HDSM & Hole drill strain measurement
\end{tabular}

power and pulse duration. Huang et al. (2016) reported that the weld deformation was linearly related to the laser power per unit length, therefore the increase in welding speed can reduce the plate deformation and the larger plates would have more out of plane deformations under the same welding conditions.

During LBW or TIG welding, a number of defects can arise due to non-uniform heating and cooling during welding operation and residual stress is one of the major defects. Goldak and Akhlaghi (2005) reported that in the process of welding, local heating of the metal led to expansion in a non-uniform manner and yielding may occur. The metal further experiences non-uniform contraction and more plastic deformation because of post weld fast cooling. In this way both the parent metal and the weld metal experiences severe thermal cycles leading to inhomogeneous plastic deformation and generation of residual stresses. Ravisankar et al. (2014) showed that for manufacturing of thin walled components, residual stresses caused the sheets to distort thus making it difficult to control the dimensions of thin components. Ferro et al. (2016) reported that residual stresses within the welded joints have a strong effect on the fatigue life of the component. Murugan et al. (2001) concluded that excessive residual stresses also led to fatigue damage, reduction in buckling strength, stress corrosion cracking and fracture and in some cases, catastrophic failure of the component. Taljat et al. (1998) reported that major factors which influence the formation of residual stresses and deformations were the weld joint types, plate thickness, metallurgical properties, welding method, restraint conditions, heat input and preheating.

A number of techniques are used to determine the surface and sub-surface residual stresses including non-destructive such as X-ray diffraction (XRD) and neutron diffraction and semidestructive like slitting, contour method and hole drilling. Lee and Liu (2009) showed that high speed hole drilling strain measurement (HDSM) technique is a very effective method, especially for thin sheets. Compared to other techniques, this method is simple, quick and reliable for determining surface and sub-surface residual stresses. It has a standard test procedure (ASTM E837, ASTM International, 2003) and simpler practical implementation. Flaman (1985) showed that for titanium alloys, use of high speed drilling produces circular, straight sided and flat bottomed hole and the residual stress distribution at depth from surface can be accurately measured. Nasim et al. (2015) used this technique to analyze the distribution of residual stresses in spiral weld pipe. Sridhar et al. (2003) investigated the effect of different machining parameters on residual stress distribution in IMI-834 titanium alloy using HDSM. Chuan et al. (2009) used this method for experimental validation of surface and sub-surface residual stress distribution in welded Ti-6Al-4V thin sheets.

Since both LBW and TIG welding are frequently used for welding of titanium alloys, their comparison from the perspective of mechanical properties and strength has always remained an area
Table 1

Chemical composition of Ti-5Al-2.5Sn (wt\%).

\begin{tabular}{llllllllll}
\hline $\mathrm{Ti}$ & $\mathrm{Al}$ & $\mathrm{Sn}$ & $\mathrm{V}$ & $\mathrm{Mo}$ & $\mathrm{Fe}$ & $\mathrm{C}$ & $\mathrm{N}$ & $\mathrm{Si}$ & $\mathrm{O}$ \\
\hline Bal. & 5.34 & 2.56 & 0.02 & $<0.01$ & 0.27 & 0.01 & 0.01 & 0.03 & 0.17 \\
\hline
\end{tabular}

of prime concern. Zhang et al. (2005) used hole drill method to determine the distribution of residual stresses in un-pulsed LBW and un-pulsed TIG weldments of BT20 and TC4 titanium alloys. They found that the spread of residual stress distribution was increased by increasing width of the weldment. Distribution of residual stresses would therefore be narrower in LBW as compared to TIG welding operations for titanium alloys and the maximum residual stress can reach up to $80 \%$ of the yield strength. They also studied the effect of post weld heat treatment (PWHT) on residual stress distribution and observed that about $90 \%$ residual stress can be relieved by vacuum PWHT. Gao et al. (2013) also showed that compared to un-pulsed TIG welding, Nd:YAG laser beam welding on Ti-6Al-4V produced less residual distortions, high Vickers hardness and narrower HAZ. Chuan et al. (2009) also showed that the spread of residual stress distribution was very narrow in continuous $\mathrm{CO}_{2}$ laser full penetration welding of Ti-6Al-4V. Pulsating of current in TIG welding was used by several researchers to improve the weld quality. Sundaresan et al. (1999) reported that pulsing of the welding current in TIG welding can also be used for grain refinement in the fusion zone (FZ) of some $\alpha-\beta$ titanium alloys. The recently published work of Mehdi et al. (2016) reported that pulsed TIG welding of Ti-6Al-4V led to a decrease in tensile residual stresses as compared to un-pulsed TIG welding.

According to Firm et al. (1994), the resistance to stress corrosion cracking of Ti-5Al-2.5Sn is less than other titanium alloys because of the presence of $\mathrm{Sn}$ and $\mathrm{Al}$ which promote the formation of $\mathrm{Ti}_{3} \mathrm{Al}$ structures. Therefore, the effect of welding process on generation of residual stresses in this alloy is of prime concern. The goal of work presented here was to get a better understanding and comparison of pulsed TIG welding (will be referred as P-TIG in this paper) and pulsed Nd:YAG laser beam welding (will be referred as P-LBW in this paper) in terms of surface and sub-surface residual stress distribution, microstructure, mechanical properties (micro-hardness and tensile properties) deformation and distortion in thin Ti-5Al$2.5 \mathrm{Sn}$ sheet. The review of literature showed that limited work was done from this aspect of comparing the pulsed form of two widely used welding techniques. The well known HDSM method was used on $1.6 \mathrm{~mm}$ thin sheet of Ti-5Al-2.5Sn alloy and results are discussed systematically.

\section{Material and methods}

\subsection{Material and welding conditions}

Full penetration Bead-on-Plate (BoP) welding was carried out on as received Ti-5Al-2.5Sn $\alpha$ titanium alloy sheet with a dimension of $100 \times 80 \times 1.6 \mathrm{~mm}$ using P-LBW and P-TIG welding processes. Chemical composition of this titanium alloy is given in Table 1.

Schematic illustrations of the two welding processes used are shown in Fig. 1. The optimized welding parameters and conditions to achieve full penetration BoP weldments for each of the welding processes are presented in Table 2 . To protect titanium surface from atmospheric reaction, argon gas was used for shielding and the weld beads having complete penetration were selected for further study. Gao et al. (2013) stated that edge preparation and filler metals are not required for the welding of thin titanium alloy sheets. Leyens and Peters (2003) reported that joint preparation before welding and use of filler material is not required for sheets having thickness less than $3 \mathrm{~mm}$. 

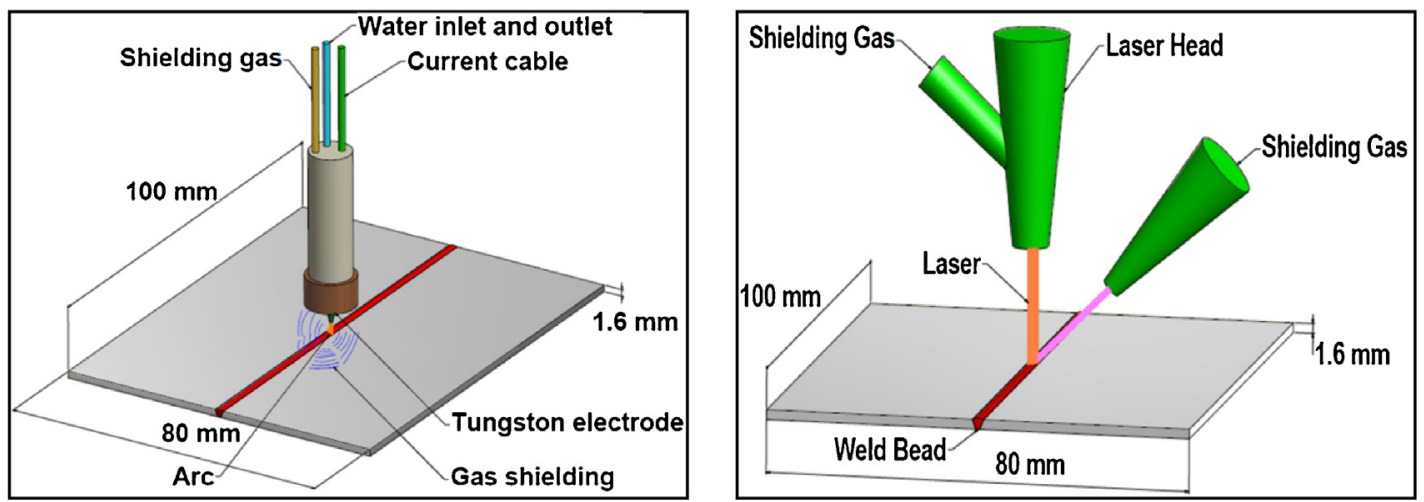

Fig. 1. Schematic illustration of welding processes: (a) P-TIG and (b) P-LBW.

Table 2

Welding parameters for P-LBW and P-TIG.

\begin{tabular}{|c|c|c|c|c|c|c|}
\hline \multicolumn{7}{|c|}{ Welding parameters for P-LBW. } \\
\hline Current & Pulse duration & Pulse frequency & y Wel & ling speed & Stand & of distance \\
\hline $260 \mathrm{~A}$ & $8 \mathrm{~ms}$ & $8 \mathrm{~Hz}$ & 160 & $\mathrm{~nm} / \mathrm{min}$ & $4 \mathrm{~mm}$ & \\
\hline \multicolumn{7}{|c|}{ Welding parameters for P-TIG. } \\
\hline \multicolumn{2}{|l|}{ Current } & \multicolumn{2}{|l|}{ Pulse width } & \multicolumn{2}{|c|}{ Welding speed } & Arc length \\
\hline Primary & Background & High Low & & & & \\
\hline $32 \mathrm{~A}$ & $16 \mathrm{~A}$ & $8 \mathrm{~ms} \quad 4 \mathrm{~ms} \quad 10$ & $10 \mathrm{~V}$ & $32.5 \mathrm{~mm} /$ & $\min$ & $4 \mathrm{~mm}$ \\
\hline
\end{tabular}

\subsection{Microstructure and mechanical properties}

Samples for metallography, micro-hardness and tensile testing comprising of fusion zone (FZ), heat affected zone (HAZ) and parent metal (PM) were wire-cut from both P-LBW and P-TIG weldments using electrical discharge machining (EDM). Metallographic samples were mechanically ground using water abrasive paper $(120,500,1200,4000$ grit) and polished with $1 \mu \mathrm{m}$ Struers diamond suspension paste. These samples were then etched first with Kroll reagent (92 $\mathrm{ml}$ distilled water, $6 \mathrm{ml} \mathrm{HNO}_{3}$ and $2 \mathrm{ml} \mathrm{HF}$ ) and

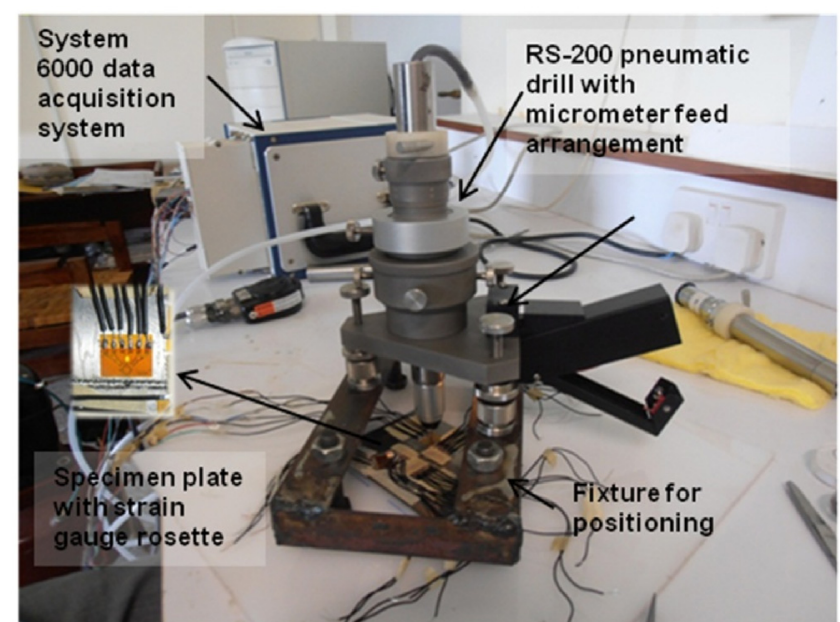

Fig. 2. Hole drill setup used for measuring residual stresses.

then with $0.2 \% \mathrm{HF}$ to reveal the microstructure. The dimensions of specimen for tensile testing were chosen according to the ASTM

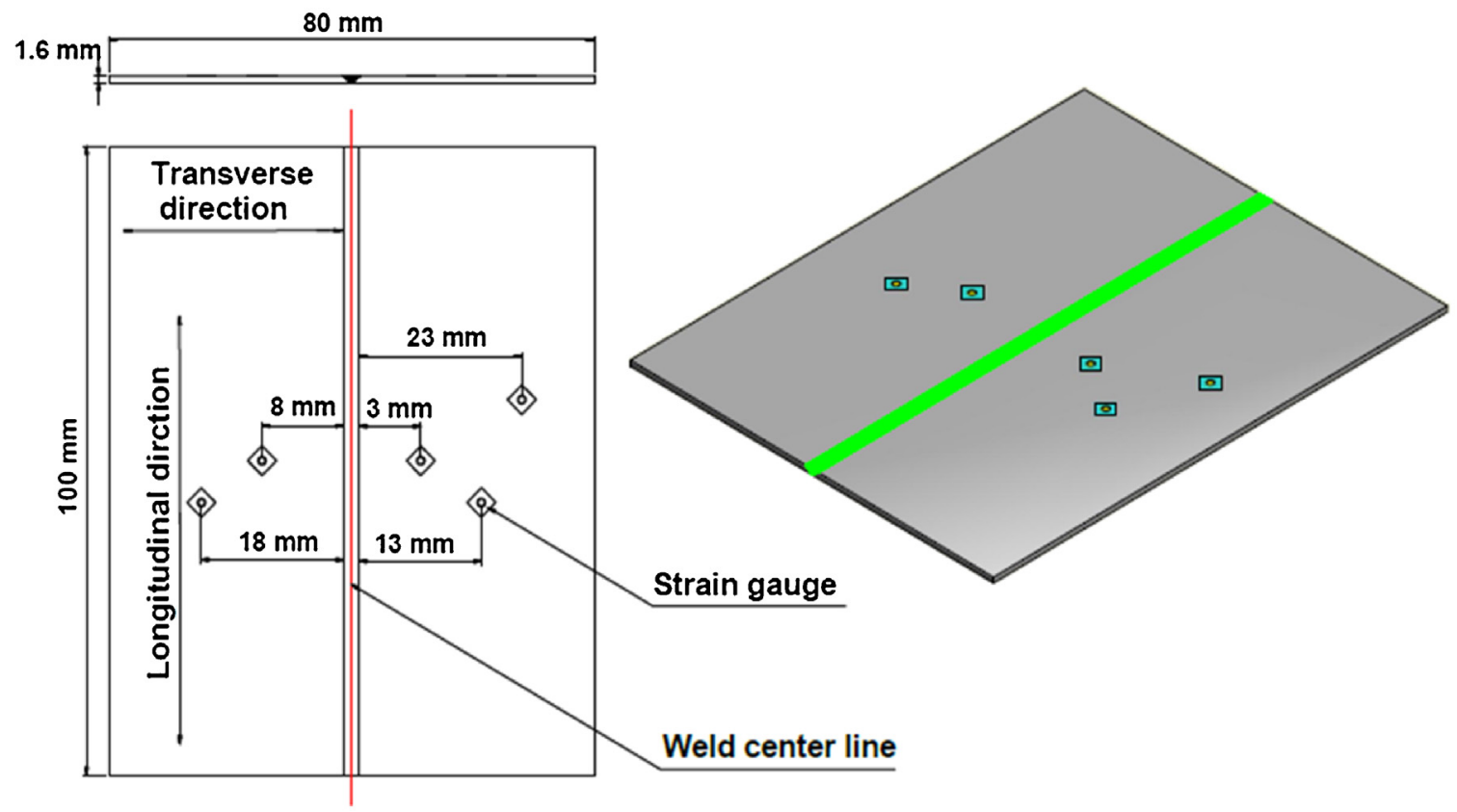

Fig. 3. Schematic showing locations of strain gauges on weldment. 
E8M-04 standard for sub size specimen (gauge length of $25 \mathrm{~mm}$ and gauge width of $6 \mathrm{~mm}$ ). Tensile tests were carried out with a $30 \mathrm{kN}$, electro-mechanically controlled INSTRON machine with a strain rate of $2.5 \mathrm{~mm} / \mathrm{min}$. Vickers hardness measurements were performed using Tukon Model 300 micro-hardness tester with a $200 \mathrm{gf}$ load and a dwell time of $10 \mathrm{~s}$.

\subsection{Measurement of residual stresses}

HDSM method was utilized in order to measure the residual stresses using the experimental setup shown in Fig. 2. It is a simple and reliable method which causes limited damage to the workpiece and is applicable to wide range of alloys for measuring the residual stresses (Rossini et al., 2012). This method is based on the elastic mechanics theory which involves positioning of a three element strain gauge rosette cemented over a specific point on the stressed plate. Drilling the hole in the center of the rosette causes strains in the vicinity of the drilled hole to be redistributed and the removal of material produces relieved strains which are measured by the nearby strain gauges.

Rosettes of type CEA-XX-062UL-120, CEA-XX-062UM-120 and EA-XX-062RE-120 were used. A hole of $1.6 \mathrm{~mm}$ diameter was drilled at the center of each rosette using high speed pneumatic drill (model RS-200 by Vishay Measurement Group, Raleigh, NC, USA). According to instructions of bulletin B-129-8 of Micro Measurements (MM) systems, before cementing the strain gauge, plate surface was gently ground with 200 and 500 grit SiC paper and then cleaned with acetone to remove scales and particles. Strain gauge rosettes were installed according to the instructions as outlined in the bulletin B-127-4. The strain gauges were soldered with wires (according to application notes TT-603, TT-606, TT-609 of $\mathrm{MM}$ ) and connected with National instruments multi-channel data acquisition system (Model SCXI-1520) with strain smart software interface. According to Application note VMM-15, resistance to ground of each strain gauge was checked to ensure that a minimum value of $10,000 \mathrm{M} \Omega$ should be obtained. Approximately $10 \mathrm{~min}$ were allowed between completion of drilling and measurement of strain data in order to avoid unstable results. For all the depth increments, a very low feed rate was used and in order to minimize the friction induced thermal effects, the drilling operation was performed intermittently by touching and removing in a continuous manner.

The locked-in stresses were determined from the released strains $\left(\varepsilon_{1}, \varepsilon_{2}, \varepsilon_{3}\right)$ of three strain gauges of the rosette by using commercially available H-Drill software developed by Gary S. Schajer and Vishay Measurements Group Inc. H-Drill is based on the procedure adopted in the ASTM E837 (ASTM International, 2003) which has the ability to find the calibration constants from hole geometry and hole depth. The non-uniform residual stresses can also be calculated from this software using either integral method or power series. Power series uses the least square method of curve fitting in the measured strain readings.

$\sigma(h)=a_{o}+a_{1} h+a_{2} h^{2}+\ldots$

In integral method for a hole of depth $\mathrm{h}$, the strain measured at a certain depth is the integral of strain components at all depth ranges. It can be expressed as

$\varepsilon(h)=\frac{1+v}{E} \int_{0}^{h} A(H, h) \sigma(H) d H, 0 \leq H \leq h$

where $A(H, h)$ is the strain relaxation per unit depth. H-Drill software uses the normalized strain data $(p, q, t)$ to assess the non-

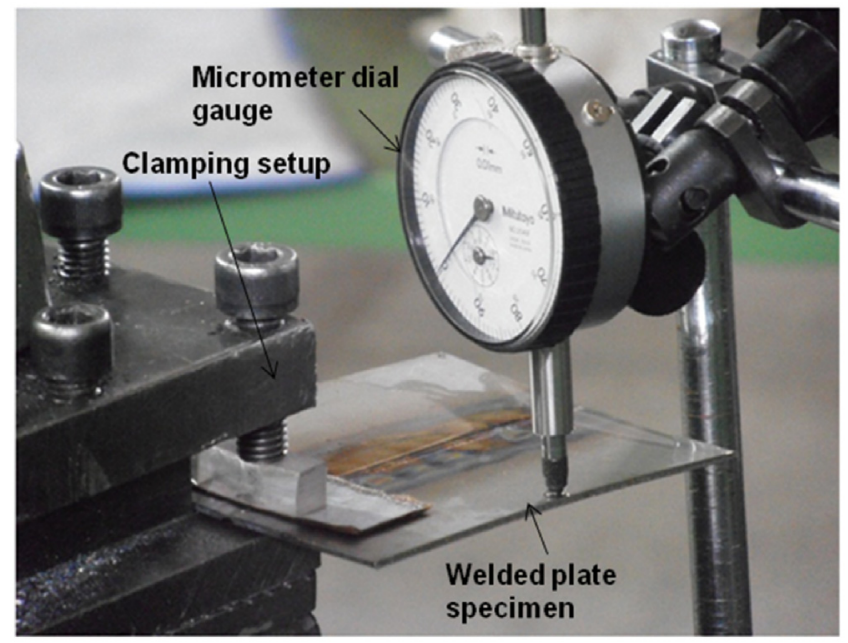

Fig. 4. Setup used for measurement of residual distortion.

uniformity in stress profile along the thickness direction. These can be expressed as

$p=\frac{\varepsilon_{1}+\varepsilon_{3}}{2}$

$q=\frac{\varepsilon_{3}-\varepsilon_{1}}{2}$

$t=\frac{\varepsilon_{1}+\varepsilon_{3}-2 \varepsilon_{2}}{2}$

The high speed drilling process itself induces a small amount of plastic strain near the edge of hole. This additional stress is taken as $20 \mathrm{MPa}$ by applying HDSM in an unstressed annealed plate.

The locations of strain gauges on welded plate are shown schematically in Fig. 3. The boundary conditions at both end of the weld center line are same, since it is a symmetrical problem. It is a justified proposition to assume that data points at either side of the weld center line and at the same distance from the center line will have the same residual stresses.

Similar symmetrical problems were also studied by Zhang et al. (2005) and Gao et al. (2013) and their conclusion was that mechanical properties at the same distance from the weld center line have same values. Based on this symmetry, Akman et al. (2009) and Kohandehghan et al. (2010) have only studied the properties on one side of the weld center line.

\subsection{Measurement of residual distortion}

To measure the residual distortion, the setup shown in Fig. 4 was used. The plates were not clamped during either of the welding processes. The effect of clamping condition on weld induced deformations have been investigated in detail by (Ma et al., 2015) and (Luo et al., 1997). They reported that although the plate distortion was reduced by clamping it, however because of a constraint on thermal expansion, strong plastic strains in the longitudinal and transverse directions were induced. This resulted in a transverse shrinkage and increase of tendon force. In this study, the plates are unclamped as the interest is in comparing the plate distortion between P-LBW and P-TIG welding. Although the residual stresses will still be present for this configuration, however the magnitude will be reduced to an extent (Ma et al., 2015). 
(a)

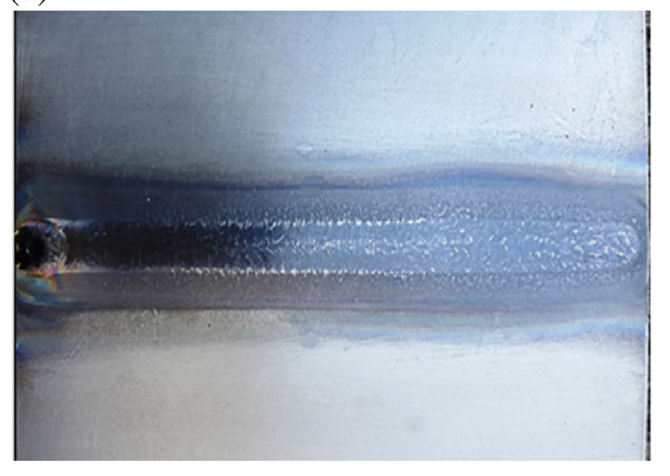

(b)

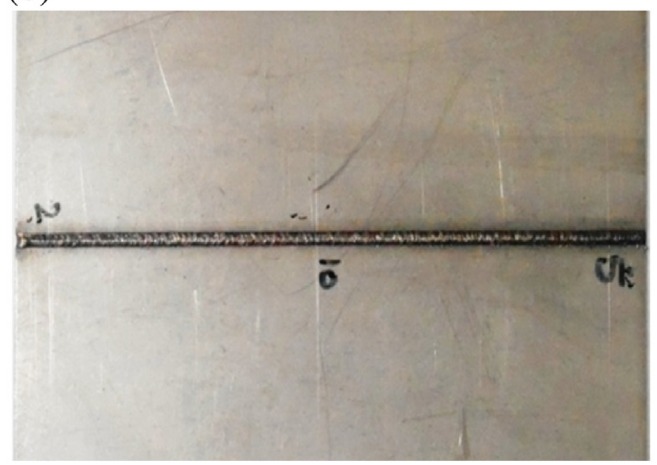

Fig. 5. Surface appearance of top side of weldments (a) P-TIG and (b) P-LBW.

Table 3

Width of FZ and HAZ of P-LBW and P-TIG weldments.

\begin{tabular}{lll}
\hline & P-TIG & P-LBW \\
\hline Top width of FZ & $6.70 \mathrm{~mm}$ & $2.01 \mathrm{~mm}$ \\
Bottom width of FZ & $4.03 \mathrm{~mm}$ & $0.52 \mathrm{~mm}$ \\
HAZ width & $7.65 \mathrm{~mm}$ & $0.75 \mathrm{~mm}$ \\
\hline
\end{tabular}

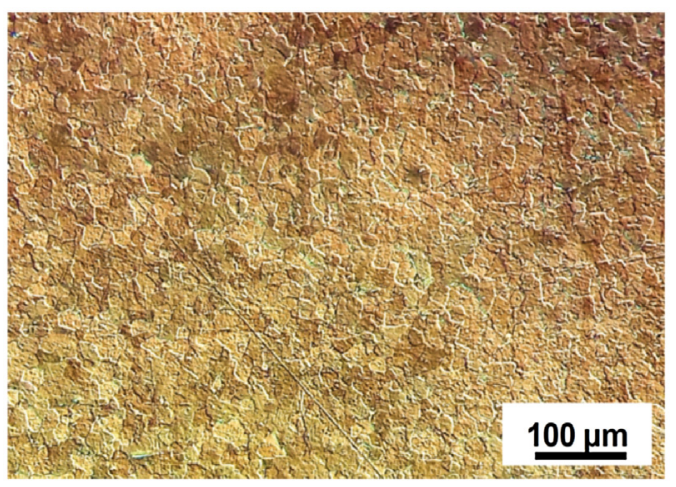

Fig. 6. Microstructure of base alloy showing equiaxed $\alpha$ grains in prior $\beta$ matrix.

\section{Results and discussion}

\subsection{Physical appearance}

Fig. 5 shows the surface appearance of P-TIG and P-LBW weldments. The surface appears to be smooth and free of oxidation, cracks and pores due to pre and post purging with the inert gas. The width of weldment for P-TIG is more than P-LBW because of higher heat input in P-TIG welding. Width of FZ and HAZ for P-TIG and P-LBW are presented in Table 3.

\subsection{Microstructural evolution}

Microstructure of the base alloy is shown in Fig. 6. The alloy consists of equiaxed $\alpha$ grains in prior $\beta$ matrix as shown in Fig. 6 .

Microstructures of different zones (FZ, HAZ and PM) of P-TIG and P-LBW weldments are shown in Figs. 7 and 8, respectively. The observed differences in microstructure of FZ, HAZ and PM are due to the extent of thermal cycles experienced by these zones. In Fig. 7(a) and (b), the interfaces between PM/HAZ and HAZ/FZ of PTIG weldment show that prior $\beta$ grains in $\mathrm{HAZ}$ and $\mathrm{FZ}$ remains more or less equiaxed as in PM however the grain size has significantly increased while going from PM to FZ. This increase in grain size is attributed to low thermal conductivity of titanium alloys in general (Karpagaraj et al., 2015). Heat is absorbed in the FZ and HAZ with peak temperatures occurring in the FZ where temperature reaches far above the melting point (MP). However in HAZ, temperature remains below the MP but there is an effect of thermal cycles occurring during welding on the microstructure. As concluded by (Karpagaraj et al., 2015) that due to low thermal conductivity of titanium, heat is retained for relatively longer time and the retention of heat near the $\beta$ transus temperature favors $\beta$ grain growth hence coarsening the grains in FZ and HAZ. (Gao et al., 2013) also confirmed a gradient in $\beta$ grain size which decreases from FZ to HAZ and PM in P-TIG welded joints of titanium alloy.

Fig. 7(c) shows the presence of some needle like $\alpha$ ' martensite along with acicular $\alpha$ within the equiaxed $\beta$ grains in FZ of TIG weldment. This confirms that diffusion less transformation of $\beta$ to $\alpha$ ' martensite has also occurred within the prior $\beta$ grains of FZ. According to Vander Voort (2004), during the cooling process, slow cooling rate transforms the high temperature $\beta$ phase to $\alpha$ which is plate like and in the form of lamellae. Retained $\beta$ can be observed in between transformed $\alpha$ layers. However, fast cooling leads to the formation of transformed $\alpha$ which is acicular in shape and is much closely packed. Further increase in cooling rate leads to the formation of fine acicular $\alpha$, often considered as needle like martensite. According to Ahmed and Rack (1998), a cooling rate of more than $410^{\circ} \mathrm{Cs}^{-1}$ is required to attain fully $\alpha$ ' martensitic structure for titanium alloys. Elmer et al. (2004) discussed in detail the time evolution of prior $\beta$ grains and subsequent $\alpha^{\prime}$ martensite formation during fast cooling in P-TIG weldments of titanium alloy. The time resolved X-Ray Diffraction (TRXRD) results in his study showed that $\beta$ is stabilized for a short period of time during cooling process and afterwards it is converted in a diffusion less manner to $\alpha$ ' martensite. He also reported a reduction in prior $\beta$ grain size while moving from FZ to HAZ. Lathabai et al. (2001) reported the coarsening of prior $\beta$ grains in HAZ near FZ boundary and also observed presence of parallel striations within each grain in P-TIG welding of pure titanium (TiG2), which is also an $\alpha$ alloy.

Comparison of Fig. 7(a) and (b) also shows some signs of needle like structure in HAZ near the FZ of P-TIG weldments which disappears towards the HAZ/PM interface. This could be $\alpha$ ' martensite or acicular $\alpha$ with retained $\beta$ in between. In the HAZ region close to PM lamella $\alpha$ appears and the acicular $\alpha$ becomes coarser. This also confirms that during heating phase of welding, temperature in HAZ close to FZ boundary crossed the $\beta$ transus and during cooling some of the retained $\beta$ is cooled fast enough to form $\alpha$ ' martensite or acicular $\alpha$. Squillace et al. (2012) reported that the cooling rate is maximum in FZ followed by HAZ. Within HAZ, the maximum cooling rate is experienced close to the FZ boundary. Hence much larger proportion of $\alpha^{\prime}$ martensite is expected in HAZ/FZ regions as compared to HAZ/PM region which is partially transformed. According to Elmer et al. (2004) in the HAZ region close to PM, temperature does not crosses the $\beta$ transus during heating and is thus a region 
(a)

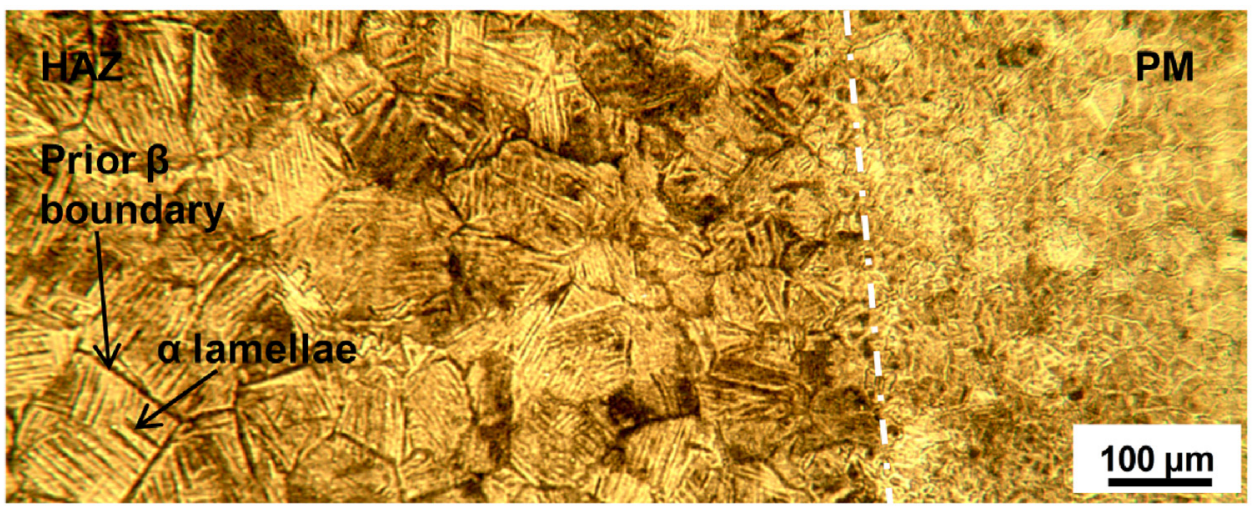

(b)

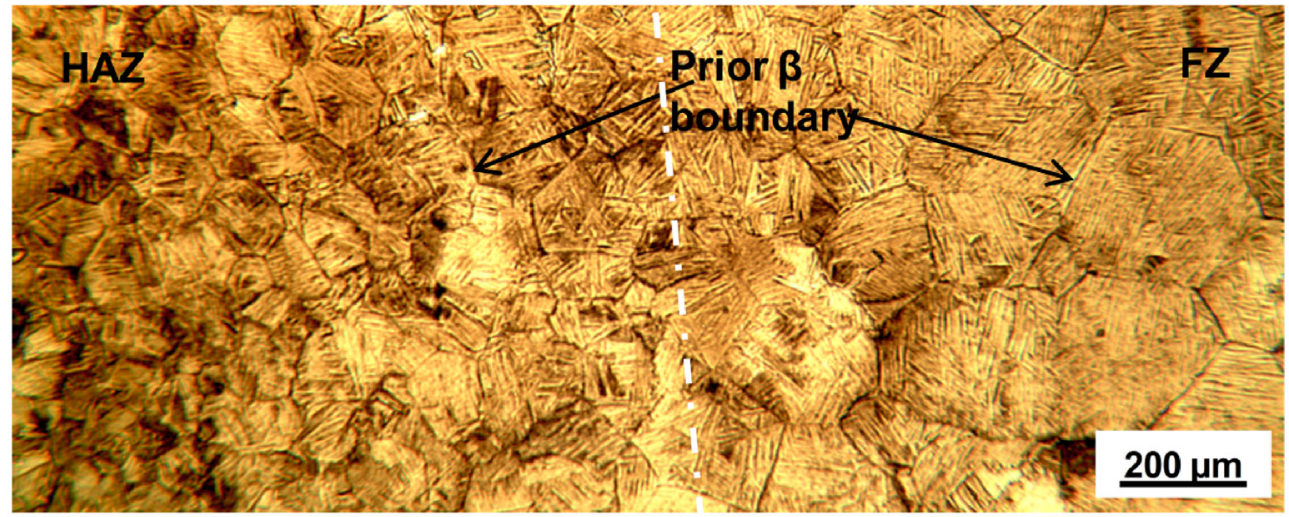

(c)

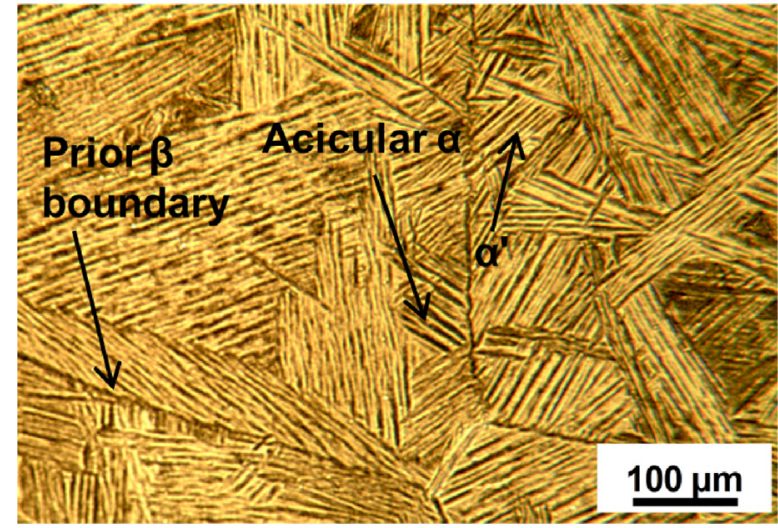

Fig. 7. Microstructures of different zones of P-TIG weldment (a) PM/HAZ interface (b) HAZ/FZ interface and (c) FZ.
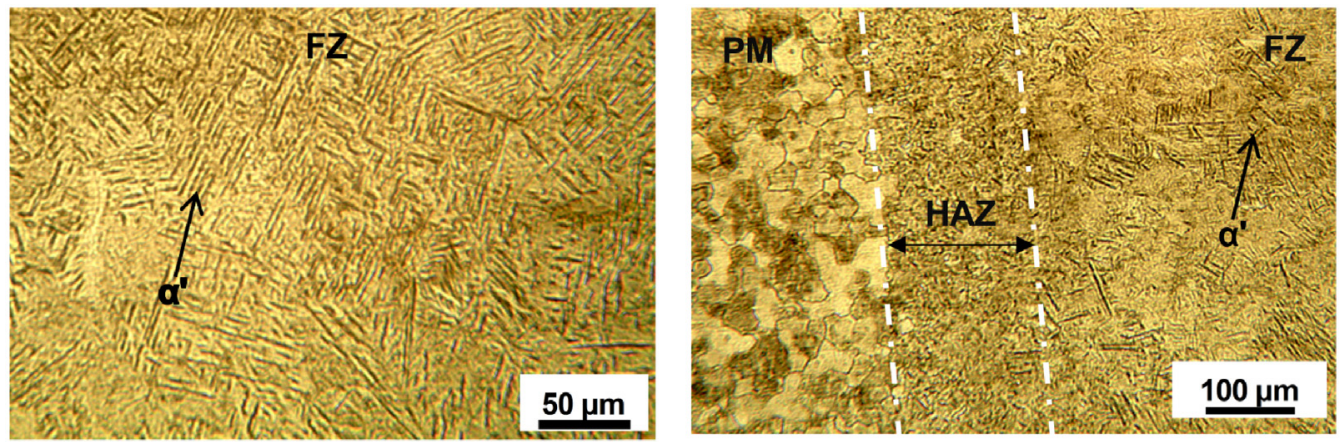

Fig. 8. Microstructures of different zones of P-LBW weldment (a) FZ and (b) FZ/HAZ/PM interfaces. 
which is quenched below the $\beta$ transus where the equilibrium fraction of $\beta$ is always less than unity. Therefore this region is deprived of $\alpha^{\prime}$ due to partial phase transformation and has a higher proportion of retained $\beta$ along with transformed lamella of $\alpha$. Gao et al. (2013) also concluded that HAZ near the PM is partially transformed due to low cooling rate while fully transformed near the FZ due to high cooling rate.

As shown in Fig. 8(a), the FZ of P-LBW weldment consists of very fine $\alpha$ ' martensite without the presence of any prior $\beta$ grains. This is due to low heat input and relatively higher cooling rate in FZ of PLBW as compared to FZ of P-TIG weldment. For $\alpha$ titanium alloys, the formation of $\alpha^{\prime}$ martensite in FZ of LBW joints was reported by Zhang et al. (2007) and Sun et al. (2003). Similarly Gao et al. (2013) reported fully martensitic grain structure in FZ of P-LBW of Ti-6Al-4V thin sheet, while in FZ of TIG joints some secondary $\alpha$ morphology along with $\alpha$ ' martensite was also observed. Elmer et al. (2004) explained that if the cooling rate is fast enough such that martensite start temperature (Ms) is reached instantly then fully $\alpha$ ' martensitic structure is achieved with no signs of prior $\beta$ grains. This is most likely the cause of much refined fully martensitic structure obtained in FZ of P-LBW as compared to FZ of P-TIG weldment. The HAZ of P-LBW, as shown in Fig. 8(b), is also complicated because of its microstructure variation while moving from FZ/HAZ boundary to PM/HAZ boundary. The first key feature is decreasing amount of orthogonally oriented $\alpha^{\prime}$ martensite from FZ/HAZ boundary to HAZ/PM boundary. This feature is also found in the HAZ of P-TIG weldment and is attributed to the decreasing cooling rate while moving from the FZ/HAZ to HAZ/PM interface. For LBW of Ti-6Al-4V, this trend is also observed by Gao et al. (2013), Cao and Jahazi (2009), Squillace et al. (2012) and Akman et al. (2009).

\subsection{Mechanical properties}

Fig. 9 shows the variation of micro-hardness from weld center line to PM in both P-TIG and P-LBW weldments. Average values of micro-hardness in FZ, HAZ and PM for both P-LBW and P-TIG are also mentioned. The significant fluctuations in Vickers hardness values is mainly attributed to observed differences in grain sizes and different phase constituents in FZ, HAZ and PM and also because of closely packed structure of titanium as concluded by Liu et al. (2011b). The average hardness of PM is about $343 \mathrm{HV}$ which is close to the value reported in literature for this alloy (Firm et al., 1994). The highest value of Vickers hardness is found in FZ of P-LBW weldment which is approximately $54.57 \mathrm{HV}$ higher than the hardness of PM. There is a very large gradient of hardness $(72.76 \mathrm{HV} / \mathrm{mm})$ between FZ and PM over a narrow HAZ of about $0.75 \mathrm{~mm}$ in P-LBW weldment which shows severe heterogeneity of mechanical properties over the width of HAZ. This is mainly attributed to the dense and narrow source of heat in P-LBW. For the P-TIG weldment, the HAZ is much wider (Table 3 ), therefore the hardness drops from FZ to PM with a gradient of approx. 3.66 HV/mm, much less compared to $72.76 \mathrm{HV} / \mathrm{mm}$ for P-LBW joints which shows consistency of mechanical properties in P-TIG welded joints.

The prior $\beta$ grain size which increases from PM to FZ in P-TIG weldment has no effect on the measured hardness distribution. This variation is rather due to the observed acicular striations which consist of $\alpha^{\prime}$ martensite and acicular $\alpha$ phase formed during fast cooling. Liu et al. (2011a) also reported grain coarsening in FZ of PLBW joints for TiG2 but attributed this increase of hardness in FZ to the structure strengthening mechanism within the prior $\beta$ grains. According to Pasang et al. (2013), the mechanism of increased hardness in FZ of $\alpha$ and $\alpha+\beta$ titanium alloys is nearly the same which is formation of $\alpha^{\prime}$ substructures, however in $\beta$ alloys, the formation of $\alpha^{\prime}$ is suppressed due to presence of $\beta$ stabilizers with a $[\mathrm{Mo}]_{\text {eq }}$ greater than 10 . Therefore for Ti-5Al-2.5Sn alloy, the trend in variation of hardness along the $\mathrm{FZ}$ and HAZ is expected to be similar to the weldments of TiG2 and Ti-6Al-4V alloy. Wang and $\mathrm{Wu}$ (2012) reported that for titanium alloys, hardness of $\beta$ phase is less than $\alpha$ or $\alpha^{\prime}$ phase while according to Zeng and Bieler (2005) the hardness and strength of these phases follow the sequence: $\alpha$ ' martensite $>$ acicular $\alpha>\beta$. Hence the boundary of HAZ having more proportion of $\beta$ phase (HAZ/PM boundary) has less hardness value compared to HAZ/FZ boundary. Moreover in P-TIG weldment, the average hardness of $\mathrm{FZ}$ is $372.38 \mathrm{HV}$ which is about $25.29 \mathrm{HV}$ less than the FZ of P-LBW weldment. This is due to the presence of acicular $\alpha$ and prior $\beta$ grains in FZ of P-TIG weldment which represents the phase constituents with reduced hardness. In FZ, the hardness is dependent on extent of $\alpha$ ' martensite formation which, in turn, is dependent on cooling rate. Gao et al. (2013), Squillace et al. (2012) and Cao and Jahazi (2009) all reported increase of hardness due to presence of $\alpha^{\prime}$ martensite and acicular $\alpha$ in FZ and HAZ of the welded joints in titanium alloys. By comparing Fig. 7(c) and Fig. 8(a), it can be seen that needle like $\alpha$ ' is finer in FZ of P-LBW as compared to FZ of P-TIG, owing to the high cooling rates in P-LBW weldment which also resulted in increased hardness.

The stress-strain relationship of tensile testing for PM, P-LBW and P-TIG weldments are shown in Fig. 10(a) and important results are summarized in Table 4. The gauge length is a composite structure of FZ, HAZ and PM for the specimens used in tensile test. This affects the tensile test results when comparing with as received alloy. Fig. 10(b) shows the optical micrographs of specimens after tensile testing. It can be seen that fracture took place in the un-welded zone of the gauge length for both P-LBW and P-TIG weldments, suggesting that the strength of weld region is more than the parent metal. Moreover, the fractured zone morphology in Fig. 10(b) shows that all three specimens exhibited ductile fracture with significant necking. Both P-LBW and P-TIG weldments exhibited nearly the same joint efficiency of approximately $95 \%$ but some loss in ductility of P-TIG weldment was observed which may be attributed to large prior $\beta$ grain size in the HAZ and FZ. Babu et al. (2007) and Mi et al. (2014) also confirmed the loss of ductility in TIG weldments of Ti-6Al-4V. Moreover, Babu et al. (2007) found that refining the prior $\beta$ grains by increasing the current pulsing causes an increase in ductility of P-TIG welds. The microstructure of FZ in P-LBW is free from coarse prior $\beta$ grains hence they exhibited nearly the same elongation as that of the parent metal. Liu et al. (2011a) also reported that the elongation at fracture of welded specimen and parent metal is same in LBW of Ti-6Al-4V alloy.

The ultimate tensile strength (UTS) values of both P-LBW and PTIG weldments are slightly less than the parent metal. This decrease in UTS is probably due to the effect of residual stresses in the welded specimens. Commin et al. (2012) reported that the results of tensile yield strength are affected by the presence of transverse residual stresses in the welded joint. It can be seen in Fig. 14 that tensile residual stresses of magnitude less than $50 \mathrm{MPa}$ are present in transverse direction at $7-10 \mathrm{~mm}$ distance from the weld center line in both P-TIG and P-LBW weldments, which is approximately the same area where fracture took place. The tensile nature of transverse component of residual stress is present in the specimen which reduces the effective yield strength during tensile testing.

\subsection{Residual stresses}

Determination of residual stresses in the FZ and PM is important because it affects the operating strength of the weldment. Commin et al. (2012) reported that presence of residual stresses in the welded structure may cause early yielding and hence they have a major influence on performance of component. The welding process involves local heating and cooling simultaneously and as the heat source moves on the titanium alloy plate, the area ahead of it suddenly heats up and the flow of argon causes very rapid cooling of 
(a)

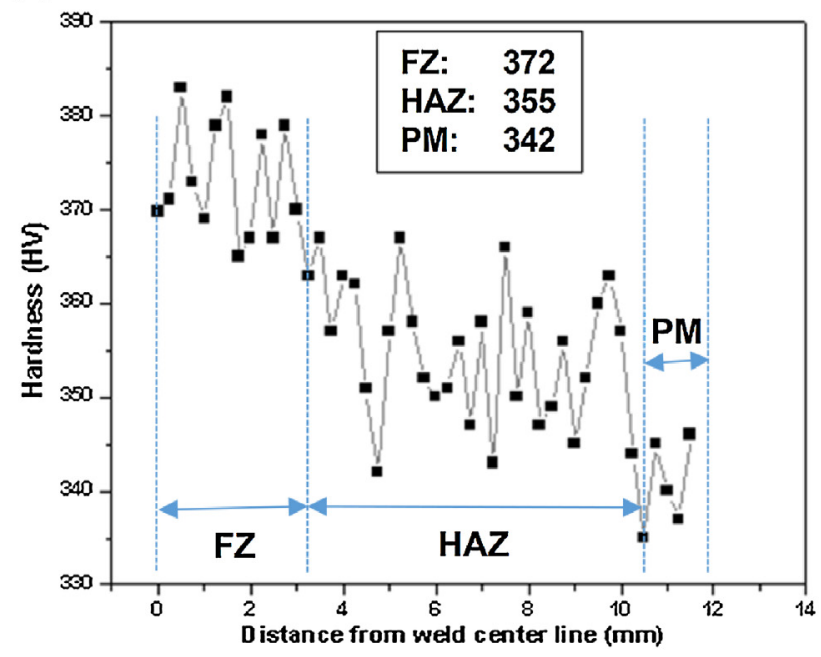

(b)

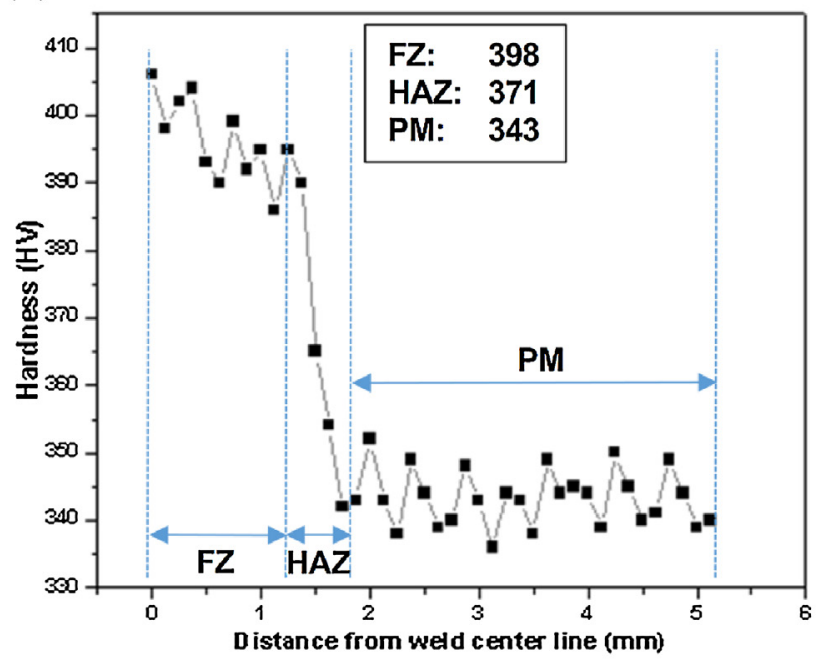

Fig. 9. Micro-hardness distribution in (a) P-TIG and (b) P-LBW weldments.

(a)

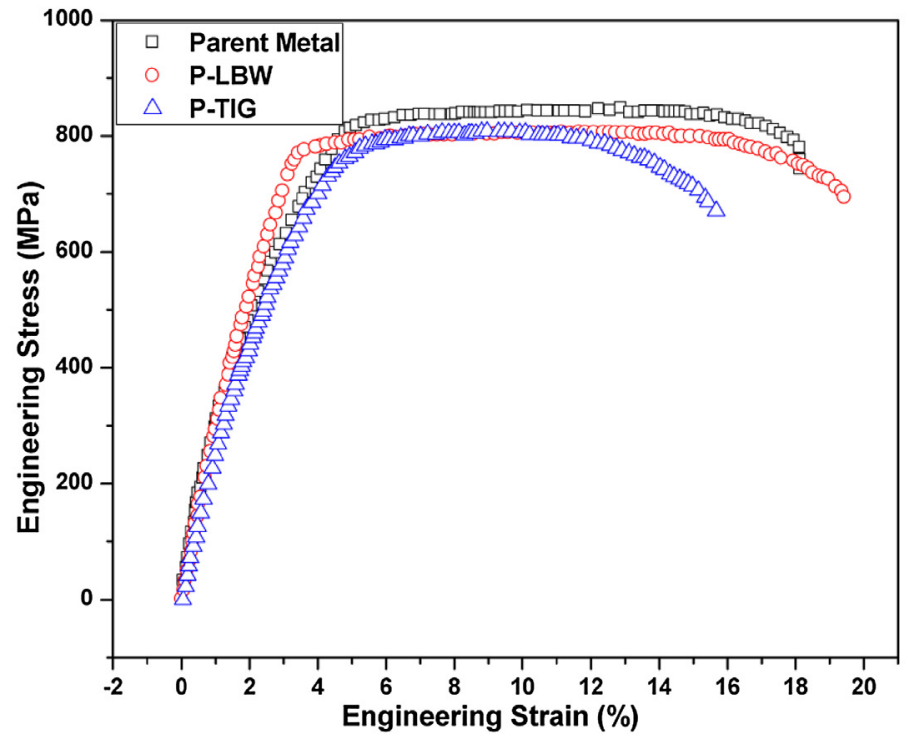

(b)
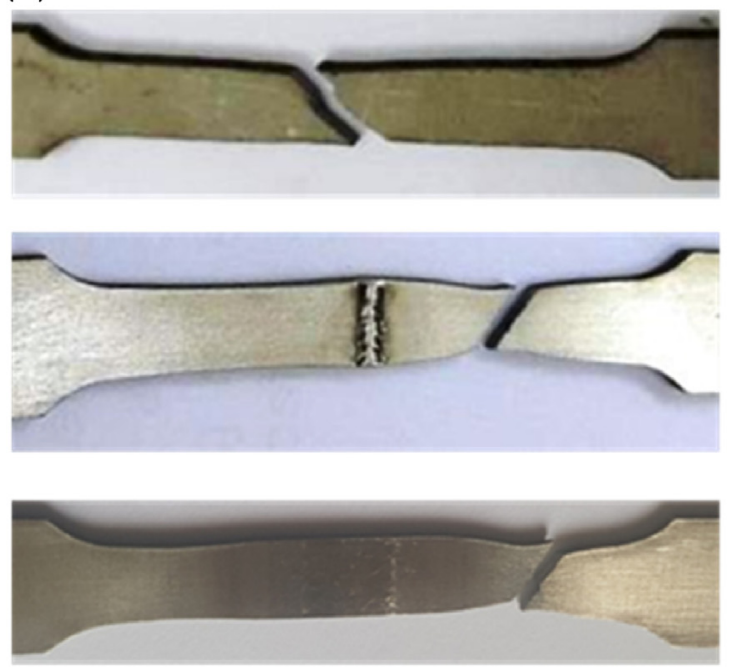

$10 \mathrm{~mm}$

Fig. 10. (a) Stress-strain curves for parent metal, P-LBW and P-TIG weldments and (b) Tensile specimens showing location of fracture.

Table 4

Summary of tensile test results.

\begin{tabular}{|c|c|c|c|c|c|}
\hline & $\mathrm{YS}_{0.2 \%}(\mathrm{MPa})$ & UTS (MPa) & \% Elongation & Joint efficiency & Fracture zone \\
\hline Parent metal & 812 & 844 & 18.12 & - & - \\
\hline P-LBW & 791 & 806 & 19.55 & 95.4 & PM \\
\hline P-TIG & 778 & 804 & 15.65 & 95.2 & PM \\
\hline
\end{tabular}

the area behind heat source. This sudden heating and cooling causes non-uniform expansion and contraction of the weld metal and since it is structurally connected with the parent metal, stresses are generated in both the sections. Moreover, microstructural changes further complicate the distribution of residual stresses. Liu et al. (2011a,b) reported that these changes include grain coarsening in FZ and HAZ due to fast cooling, substructure strengthening and solid solution strengthening. The complexity of process requires evaluation of residual stresses in the entire structure (length, width and thickness) to completely determine the level of induced residual stresses.
Schajer (1981) reported that one of the advantages of HDSM is to predict with acceptable accuracy the residual stresses at a depth less than hole diameter from the surface of the plate. The trend in non-uniformity of through thickness stress profile can be predicted by comparing the strains relieved during the incremental hole drilling with the experimental results of Rendler and Vigness (1966). Their proposed criterion was applied to the present case as shown in Figs. 11 and 12 for P-TIG and P-LBW, respectively. Here the solid lines represent $P$ and $Q$ strains (Eqs. (3)-(5)) for a uniform case from the two investigators (Rendler and Vigness, 1966) while the data points represent the relieved strains in the present study. 
(a)

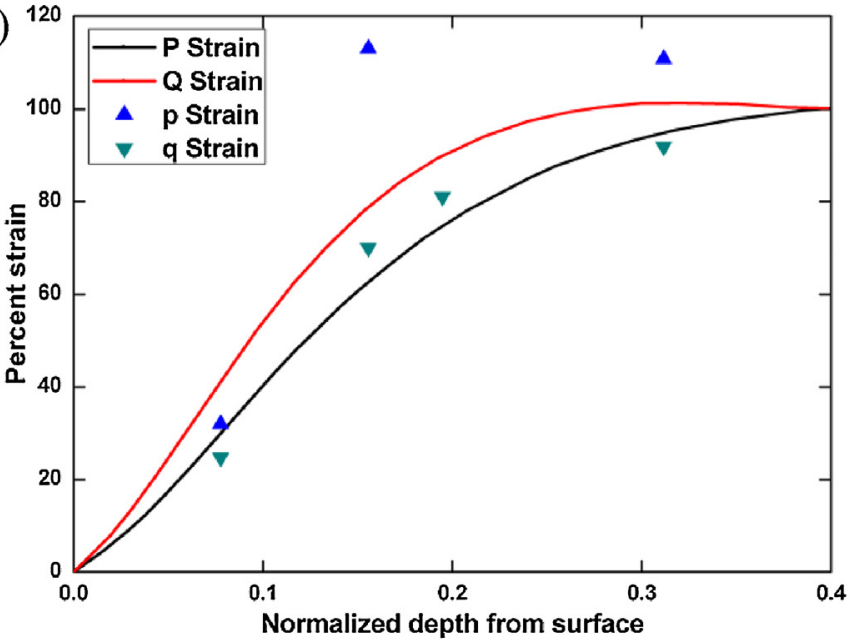

(b)

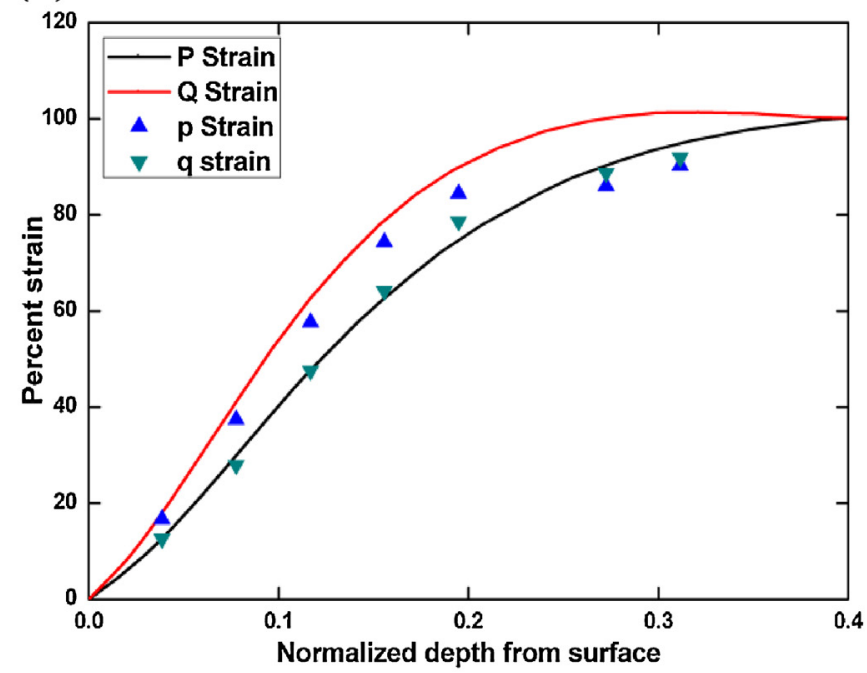

(d)

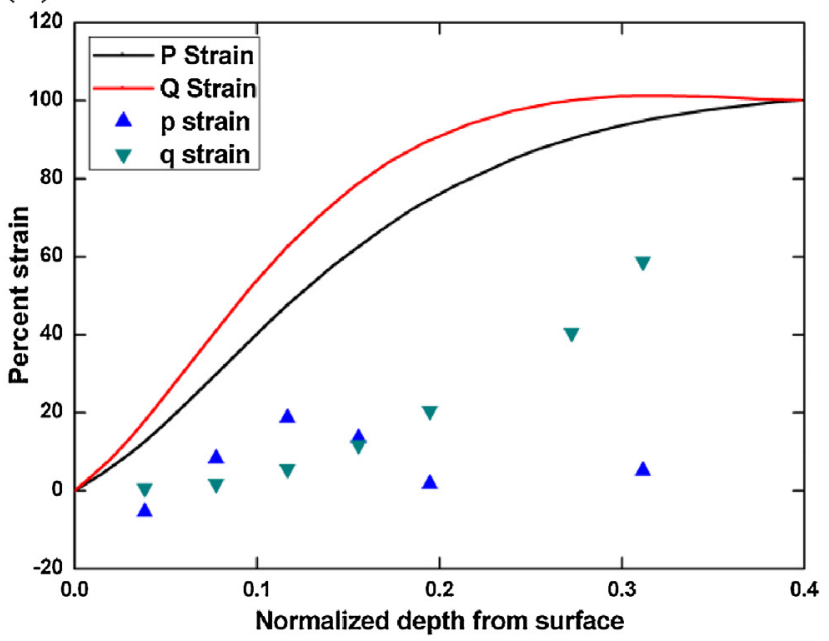

(c)

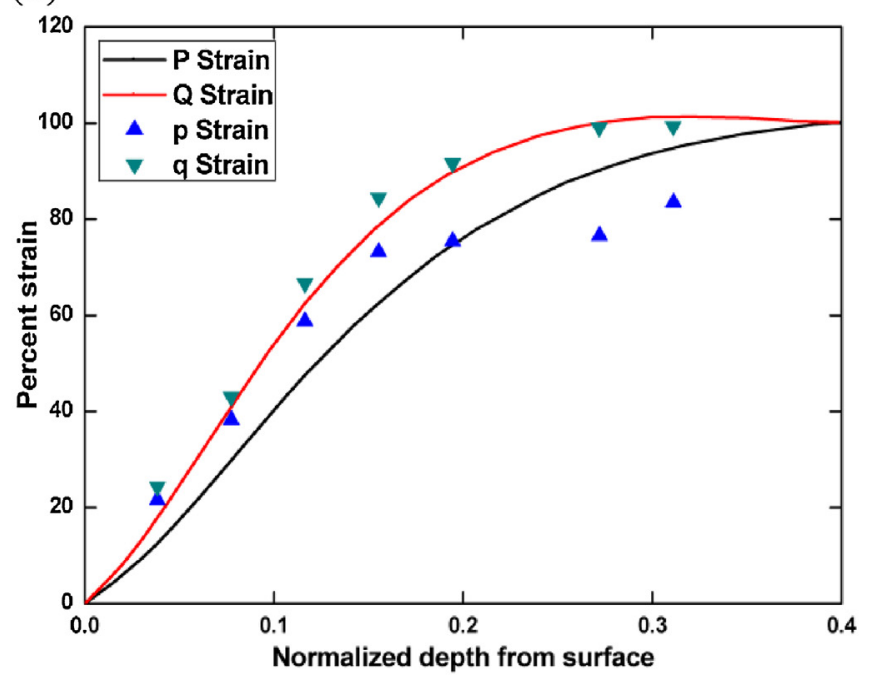

(e)

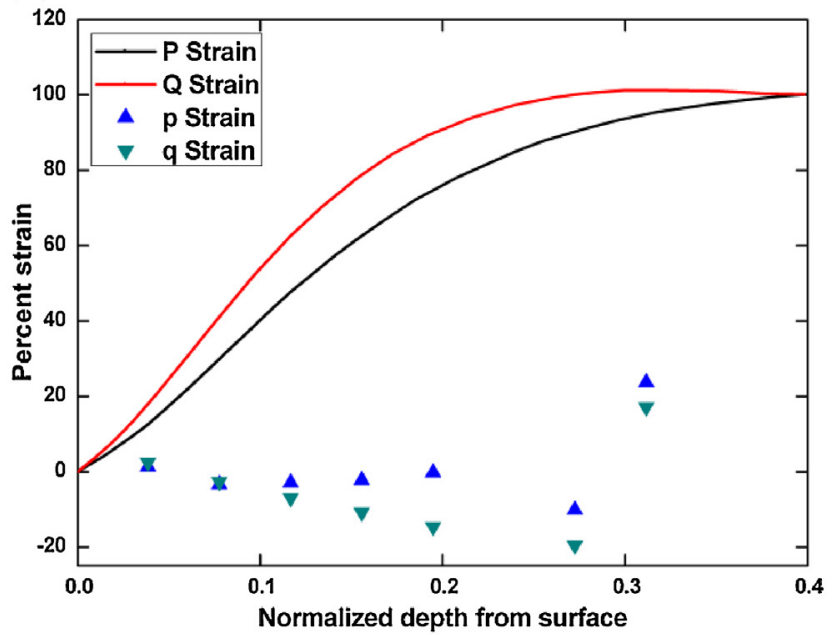

Fig. 11. Percent relieved strain vs. normalized hole depth for P-TIG weldment at (a) $3 \mathrm{~mm}$ (b) $8 \mathrm{~mm}$ (c) $13 \mathrm{~mm}$ (d) $18 \mathrm{~mm}$ and (e) $23 \mathrm{~mm}$ distance from weld center line.

It can be seen in Fig. 11 that for P-TIG weldment there is a little non-uniformity in residual stress profile at locations $3 \mathrm{~mm}, 8 \mathrm{~mm}$ and $13 \mathrm{~mm}$ from the weld center line as not all the relieved strain data points for these locations lie within the solid lines of $\mathrm{P}$ and $\mathrm{Q}$ strains. The location at $8 \mathrm{~mm}$ has the relieved strain data closest to the solid $\mathrm{P}$ and $\mathrm{Q}$ curves and it is expected that this point will have little variation of residual stress with depth. This uniformity can be observed in the actual stress curves of P-TIG weldment at this location in Figs. 13 (a) and 14 (a) where the values of residual stress in longitudinal and transverse direction at different depths are much closer to each other. However the analysis shows that the locations at $13 \mathrm{~mm}$ and $23 \mathrm{~mm}$ in P-TIG weldment have a highly 
(a)

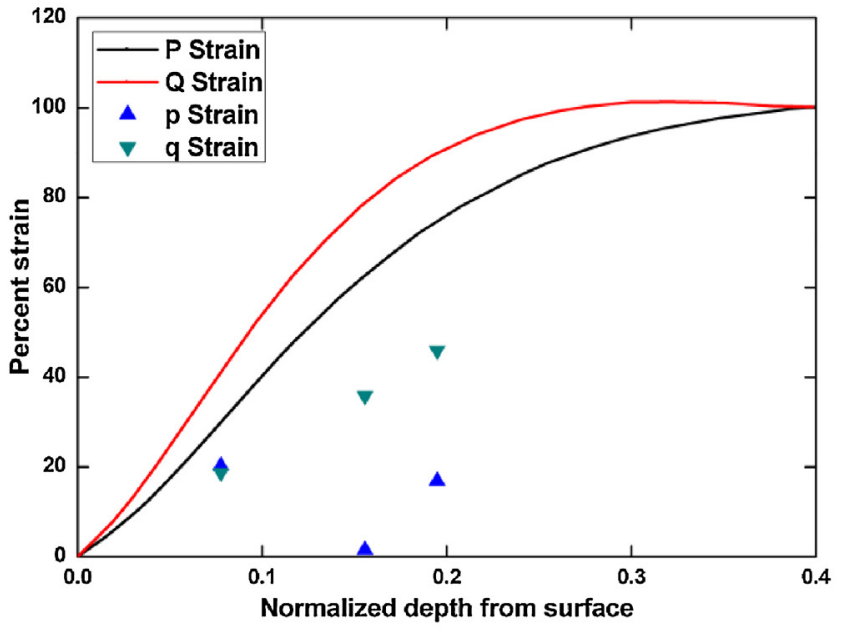

(b)

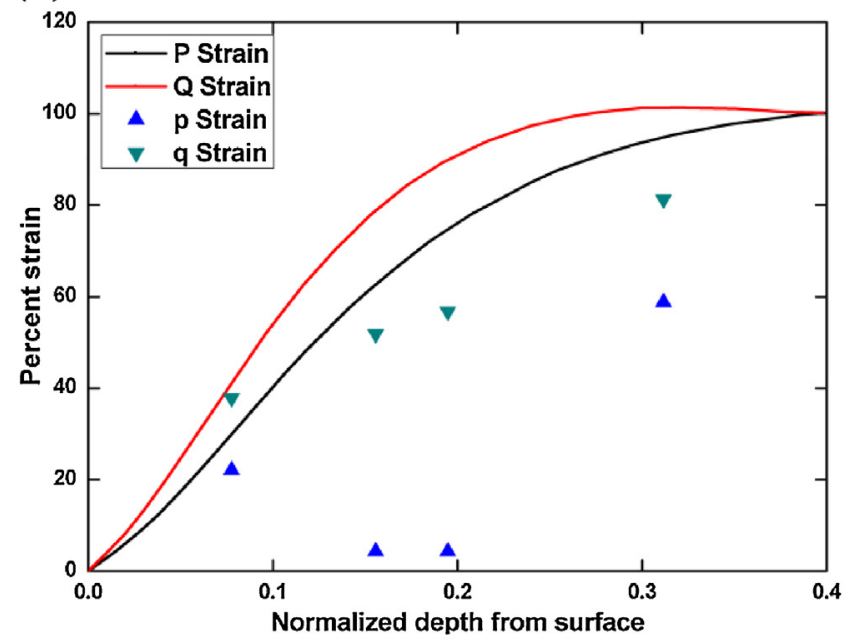

(d)

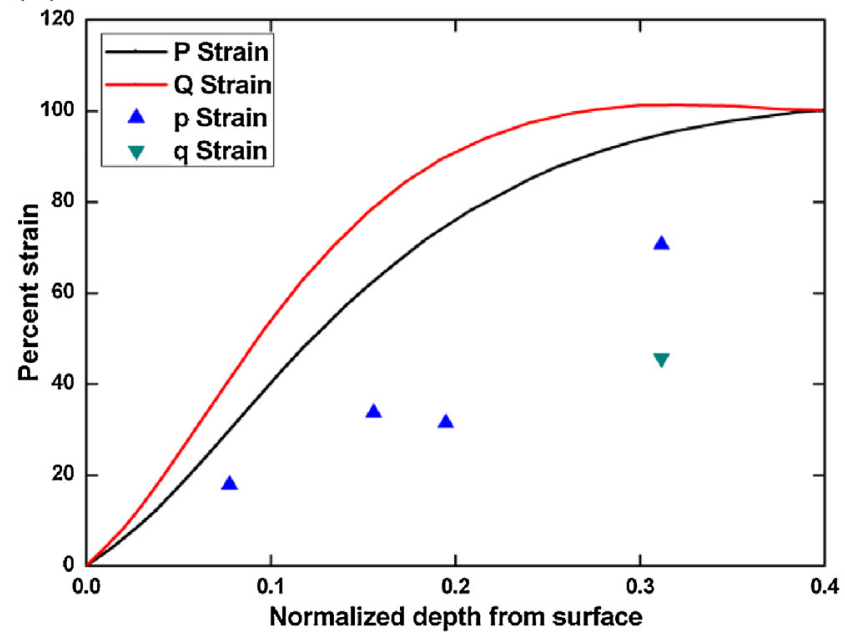

(c)

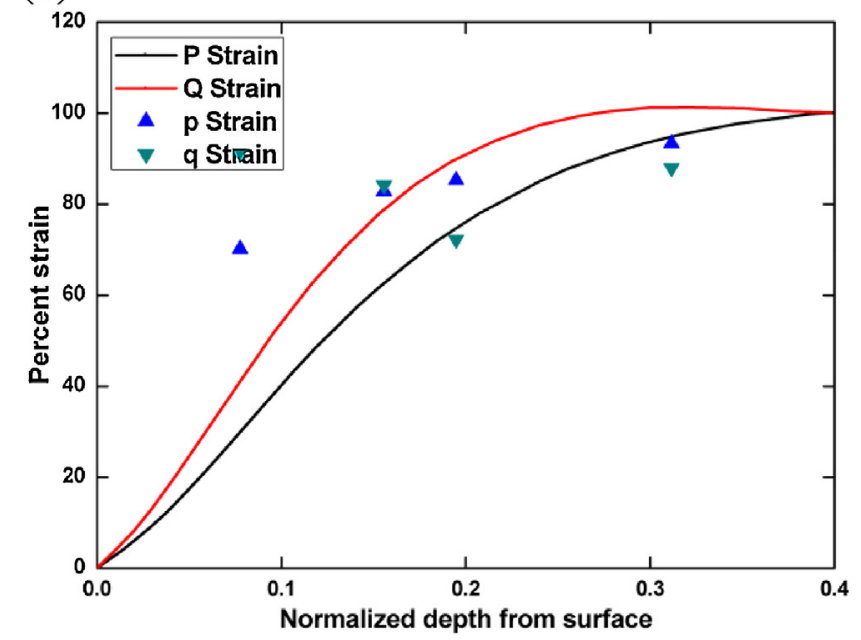

(e)

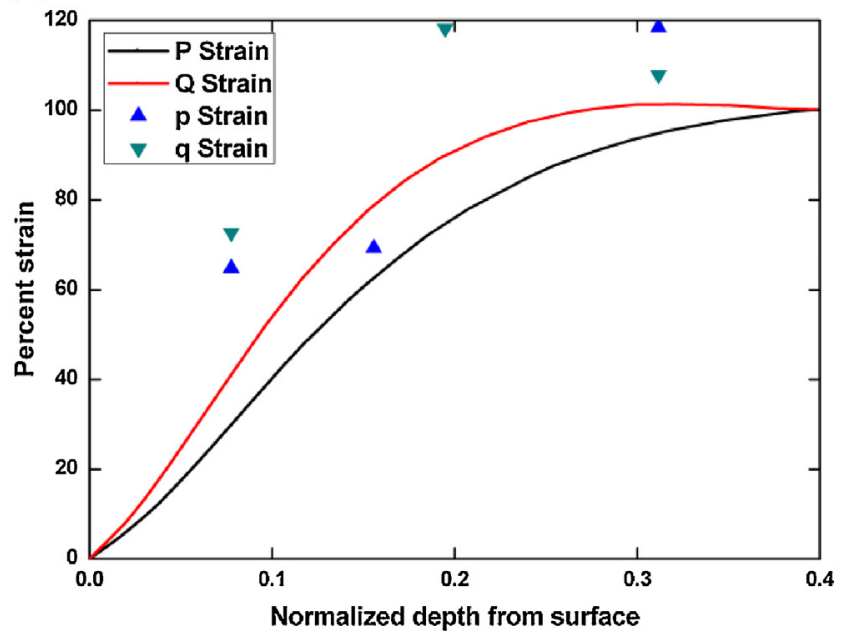

Fig. 12. Percent relieved strain vs. normalized hole depth for P-LBW weldment at (a) $3 \mathrm{~mm}$ (b) $8 \mathrm{~mm}$ (c) $13 \mathrm{~mm}$ (d) $18 \mathrm{~mm}$ and (e) $23 \mathrm{~mm}$ distance from weld center line.

non-uniform through thickness stress profiles as the data points are further away from the solid lines.

For the P-LBW weldment, through thickness stress distribution is highly non-uniform as almost all the measured strain data points are outside the region enclosed by $\mathrm{P}$ and $\mathrm{Q}$ curves. Residual stress evaluation for titanium alloys reported by other researchers in PTIG and P-LBW have assumed uniform stress distribution while applying the hole drill method (Zhang et al., 2005). However, the uniformity in through thickness stress profile cannot be applied in general to the phenomena of welding because of non-uniform expansion and contraction associated with it. In the work of Chuan et al. (2009), the finite element simulations carried out on full penetration weld of a $4 \mathrm{~mm}$ sheet of titanium alloy showed that stresses are non-uniform throughout the thickness. 
(a)

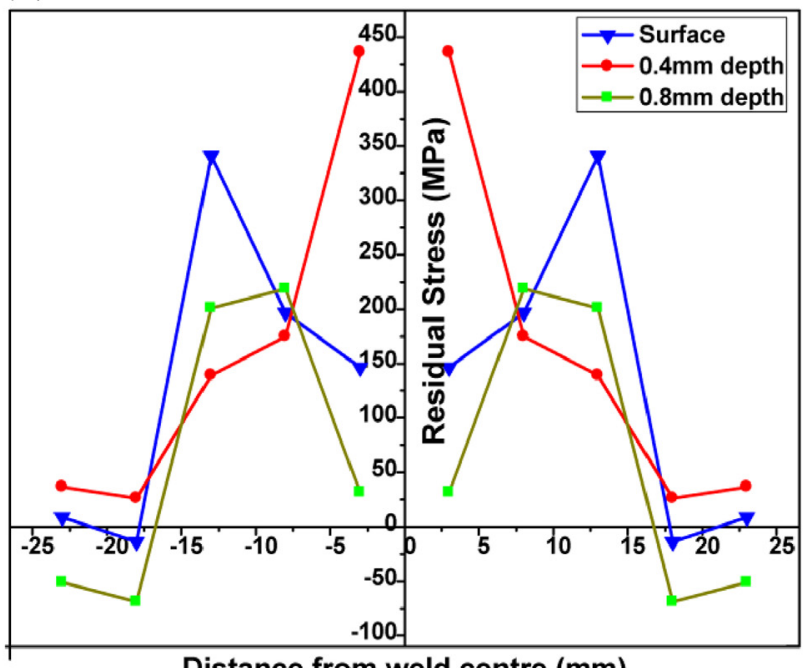

Distance from weld centre $(\mathrm{mm})$ (b)

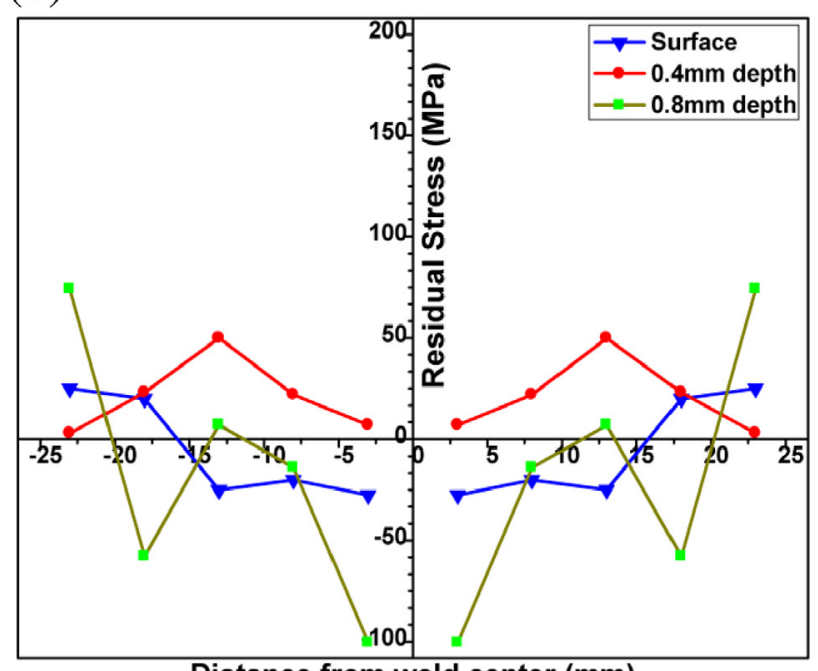

Distance from weld center $(\mathrm{mm})$

Fig. 13. Longitudinal residual stress distribution at different depths in (a) P-TIG and (b) P-LBW weldments.

(a)

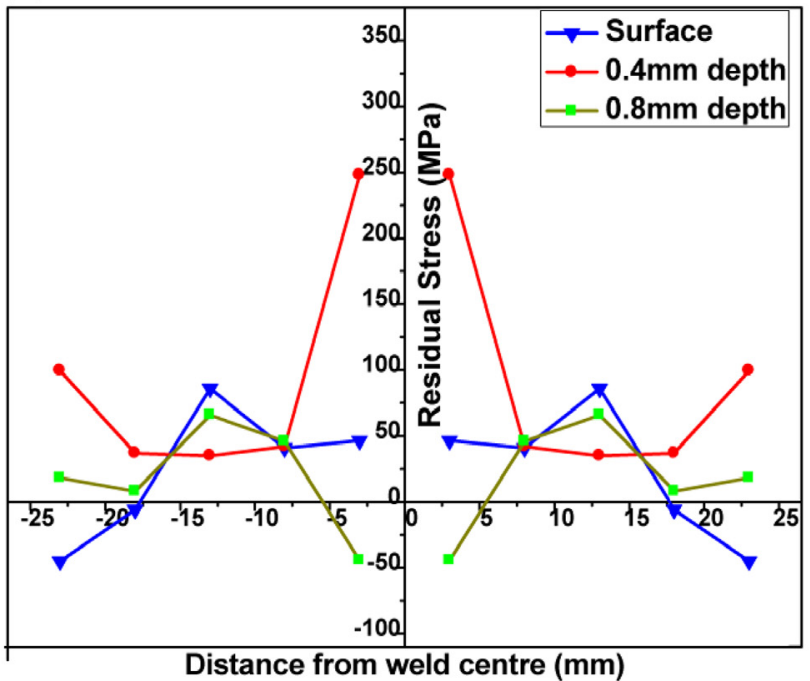

(b)

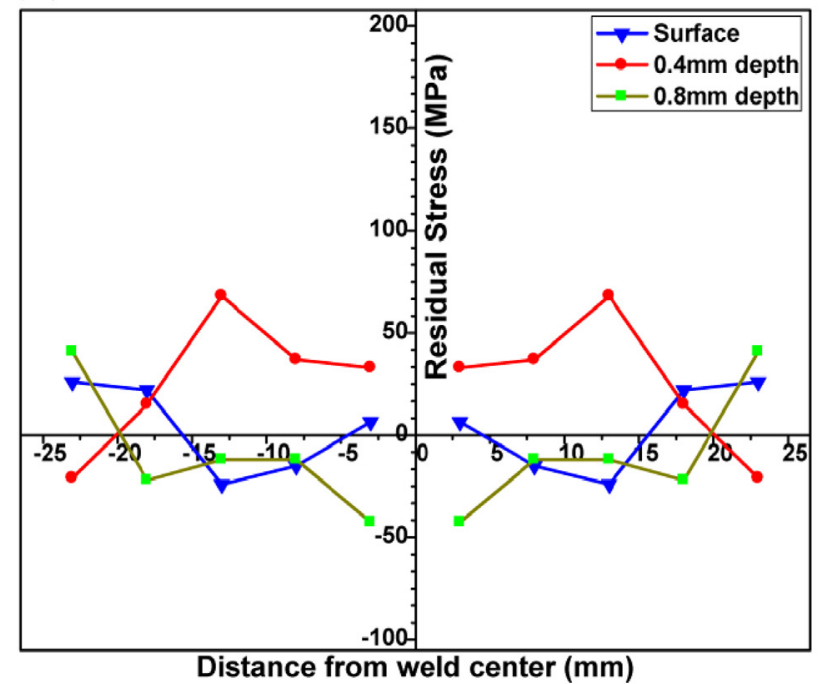

Fig. 14. Transverse residual stress distribution at different depths in (a) P-TIG and (b) P-LBW weldments.

To compute the residual stresses, relieved strain data after each depth increment can be analyzed using either the integral method or uniform stress or Power series approach. The comparison of these analysis approaches has been done by Grant et al. (2006) using two samples of pre-stressed plates with a known state of stress. On one plate the pre stressed state was uniform (center plug in a "ring and plug" interface fit component) and on other, it was highly non-uniform (shot peening on aluminum sample). It was concluded that integral method gives the best results for nonuniform state of stress and therefore was used in the present work. Based on this method, the longitudinal residual stress distribution in P-TIG and P-LBW weldments is compared at different depths as shown in Fig. 13. It shows that the P-TIG weldment has tensile stresses close to the weld center line at all depths. The maximum value of tensile stress is about $430 \mathrm{MPa}$ at a distance of $3 \mathrm{~mm}$ from weld center line and is not at the surface but at a depth of about $0.4 \mathrm{~mm}$ below the surface. It is expected that at the weld center line, these maximum stresses will be close to the yield strength.
The residual stress distribution in P-LBW weldment (Figs. 13 (b) and 14 (b)) shows that there is no location at which stress values at different depths are close to each other which lies in agreement with the results shown in Fig. 12. For P-LBW weldment, the nonuniformity of residual stresses in the direction of thickness may be attributed to the change in width of FZ from top to bottom surface of plate which is $2.01 \mathrm{~mm}$ and $0.52 \mathrm{~mm}$, respectively. Residual stresses are generated after welding, because the molten material cools at a very fast rate and contracts but as it is being held by the parent plate, the constraint to maintain original length causes deformation and stresses in the plate. In this way the weld center line experiences longitudinal tensile stresses while the parent plate is under compressive stress. To a smaller extent, this phenomenon happens in the transverse direction as well, and as the width of weld pool cools and contracts, the plate tries to maintain its width and hence experiences distortion and residual stresses. Since the molten metal in FZ of P-LBW has uneven width at top and bottom surface, the level of contraction due to cooling is uneven at different depths which results in variation of residual stresses 
with depth from surface. This effect also causes residual distortion which is more prominent in thinner plates. The FZ width at top and bottom surface for P-TIG weldment is $6.70 \mathrm{~mm}$ and $4.03 \mathrm{~mm}$, respectively. For this case the top to bottom FZ width ratio is 1.66 , while for P-LBW it is 3.86. The higher width ratio in P-LBW leads to greater extent of uneven metal contraction with depth in the FZ. On the contrary, due to reduced top to bottom FZ width ratio, the metal contraction with depth will not be much prominent in P-TIG weldment, hence through thickness stress profile is relatively uniform. However as P-TIG weldment has higher stress induced distortion, the associated bending causes additional stress difference between plate layers at different depths.

For P-LBW weldment, the residual stresses at location closest to weld center line ( $3 \mathrm{~mm}$ ) are quite low compared to P-TIG weldment (Fig. 15). The work reported on P-LBW weld residual stresses by Zhang et al. (2005) and Chuan et al. (2009) shows that stress gradients are very steep close to weld center line with tensile stresses near the weld center line shifting to compressive within distance of first few millimeters. Therefore, it is expected that in the present case of P-LBW weldment tensile stresses are present at the weld center line but due to practical limitations of weldment roughness, strain gauge rosette could not be installed at any location closer than $3 \mathrm{~mm}$ to weld center line. Since compressive stresses of about $100 \mathrm{MPa}$ are observed at $3 \mathrm{~mm}$ from weld center line it can be concluded that the stress mode has transformed from tensile to compressive, before $3 \mathrm{~mm}$ to weld center line. Therefore, the stress distribution in P-LBW weldment close to weld center line has very steep gradients as compared to stresses in P-TIG weldment. For PTIG weldment, tensile residual stresses are present at all depth until a distance of about $18 \mathrm{~mm}$ from the weld center line from where onwards the nature of these stresses becomes compressive.

The longitudinal stress distribution for P-LBW and P-TIG weldments at surface and a depth of $0.4 \mathrm{~mm}$ and $0.8 \mathrm{~mm}$ are compared in Fig. 15 which shows that the residual stress distribution in P-TIG weldment is much wider than P-LBW. Zhang et al. (2005) attributed this to stress distribution being in positive proportion to the width of weldment. In the present case, Table 3 shows that the total width of P-TIG weld is about $19 \mathrm{~mm}$ more than P-LBW so tensile stresses are spread at a much wider zone in P-TIG weldment. Zhang et al. (2005) also showed that in order to achieve the full penetration in $2 \mathrm{~mm}$ thick sheet of BT20 and TC4 titanium alloys, P-TIG welding generates significantly higher longitudinal residual stresses than PLBW. This behavior is clearly observed in Fig. 13 at all depths below the surface. The increased value of residual stress and angular distortion in P-TIG welding can also be explained on the basis of weld heat input. Murakawa (2013) reported that welding distortions and residual stresses are strongly influenced by welding heat input, therefore higher residual stresses will be induced by higher heat input. Short (2009) reported that P-LBW has higher power density than P-TIG welding therefore to achieve penetration through the same thickness of material, P-TIG welding imparts more heat input and induces more stresses and deformations (Fig. 16). Although thermal strains have a major effect on residual stress distribution, phase transformations during cooling of the weldments also influenced the magnitude of residual stresses, especially close to the weld center line. Appolaire et al. (2015), reported that the formation of $\alpha^{\prime}$ martensite or transformation from $\beta$ to $\alpha$ phase during the cooling process led to an increase in local volume of the material which generated compressive stresses. In Figs. 13 (b) and 14 (b), the lower values of residual stresses close to weld center line of P-LBW weldment may be due to the induced compressive residual stresses during formation of fully martensitic $\alpha$ ' phase in FZ. These compressive stresses lessen the effect of tensile stresses induced due to thermal strains at locations close to weld center line. This phenomena also took place close to the weld center line of P-TIG weldment.However compared to P-LBW, less $\beta$ to $\alpha$ ' transforma- tion takes place due to which relatively less compressive stresses associated with volumetric change are induced.

Transverse stress distribution for both P-TIG and P-LBW weldments is shown in Fig. 14. It can be observed that overall magnitude of transverse stresses is significantly less than longitudinal stresses for both P-TIG and P-LBW weldments. The work of Zhang et al. (2005) and Chuan et al. (2009) showed that during P-TIG and PLBW welding of thin sheets, longitudinal stresses were higher than transverse and hence of critical importance. Moreover in addition to titanium alloys, this behavior was observed in work done on other alloys as well (Deng and Murakawa, 2008; Leggatt, 2008; Barroso et al., 2010). The prime reason for this behavior is a very sharp temperature gradient along the weld direction (longitudinal direction). Furthermore, it is expected that due to unclamped setup, overall severity of stresses in Figs. 13 and 14 is partially relieved as the sheet relaxes under influence of internal residual stresses. Ma et al. (2015) reported that for clamped plates residual stresses are relatively higher than unclamped plates.

\subsection{Deformations and distortions}

In the present work, the plates were not clamped during welding process so that the plate distortion after welding can be observed. The effect of clamping conditions on weld induced deformations has been investigated in detail by Ma et al. (2015) and Luo et al. (1997). They reported that although the plate distortion was reduced by clamping it but because of a constraint on thermal expansion, strong plastic strains in the longitudinal and transverse directions were induced. This resulted in a transverse shrinkage and increase of tendon force. Nevertheless, residual stresses will still be present for unclamped setup but the magnitude will be reduced to an extent as deducted from the work carried out by Ma et al. (2015).

The variation of angular deformation along the longitudinal axis for both weldments is shown in Fig. 17(a) which shows that angular distortion produced by P-TIG welding is much larger in magnitude than P-LBW. For P-TIG welding, the maximum angular distortion is approximately $6.3^{\circ}$ and for P-LBW it is $0.91^{\circ}$, which gradually increases towards the end of the plate. Similar trend was also reported by Ma et al. (2015) and Brien and William (2007) for free non constraint condition for SS 304 and SS 400 steels, respectively. The trend of deflection observed in Fig. 17(b) shows that plate along weld center line has deformed more than the outer rim. Long et al. (2009) attributed this effect to relatively higher longitudinal shrinkages at weld center line than at a distance.

Fig. 17(c) compares the transverse shrinkage for P-LBW and PTIG welding and it can be seen that owning to less overall heat input, the shrinkage in P-LBW weldment is significantly less than in P-TIG weldment. Moreover, the overall value of transverse shrinkage for both P-LBW and P-TIG weldments decreased towards the finishing end. Ma et al. (2015) concluded that this behavior is because of less compressive plastic strains due to weak internal constraints.

\section{Conclusions}

- For P-TIG weldments, the equiaxed $\alpha$ grains of PM became larger in size in HAZ and FZ. $\alpha$ ' martensite and acicular $\alpha$ was observed in FZ and FZ/HAZ boundary which led to increase of micro-hardness in FZ. For P-LBW, fully $\alpha$ ' martensitic structure was observed in FZ due to low heat input and highest cooling rate resulting in hardness of $398 \mathrm{HV}$ which is approximately $26 \mathrm{HV}$ more than hardness of FZ in P-TIG weldment.

- For both P-LBW and P-TIG, tensile testing resulted in a ductile fracture in un-welded zone of the specimen which showed that welded zone is stronger than BM. The presence of coarse prior 
(a)

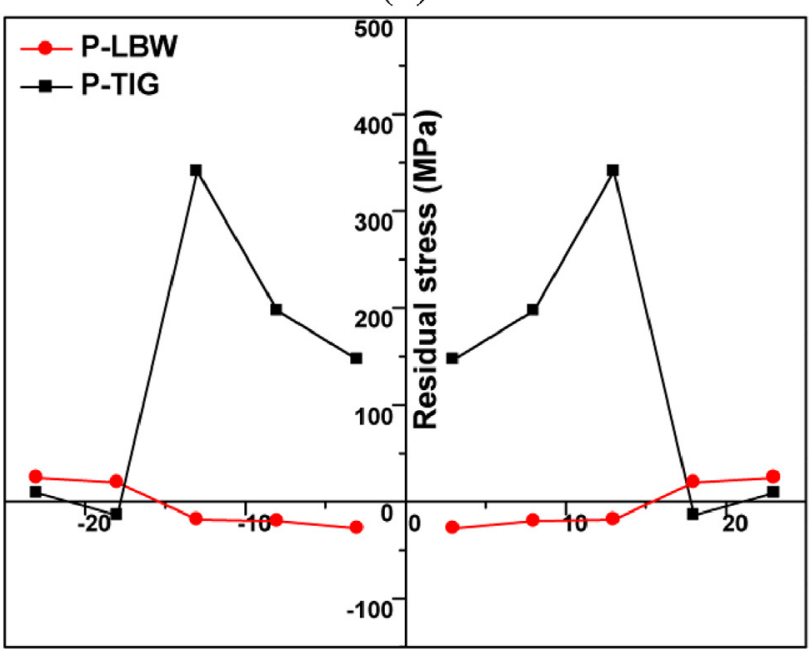

Distance from weld center $(\mathrm{mm})$

(b)

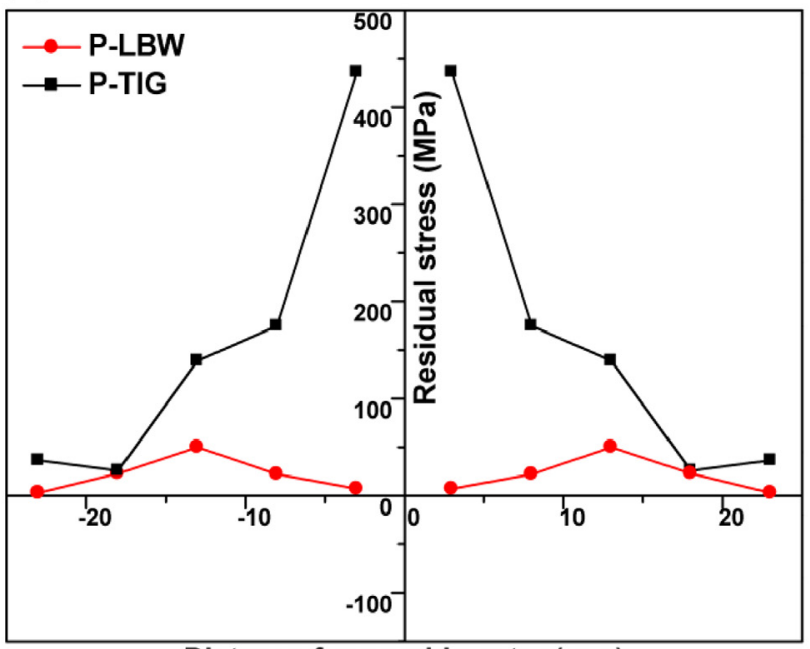

Distance from weld center $(\mathrm{mm})$ (c)

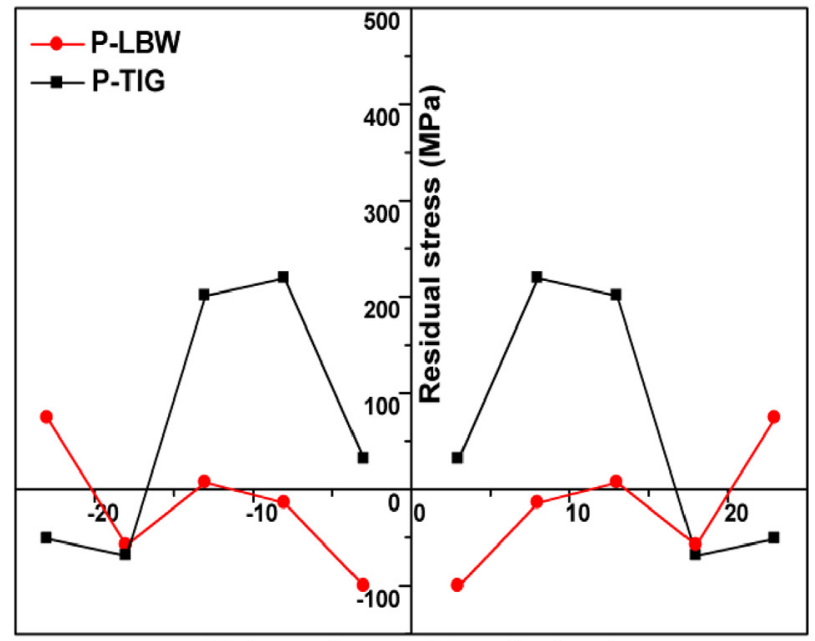

Distance from weld center $(\mathrm{mm})$

Fig. 15. Comparison of longitudnal residual stresses in P-LBW and P-TIG weldments (a) at surface (b) at $0.4 \mathrm{~mm}$ depth and (c) at $0.8 \mathrm{~mm}$ depth.

(a)

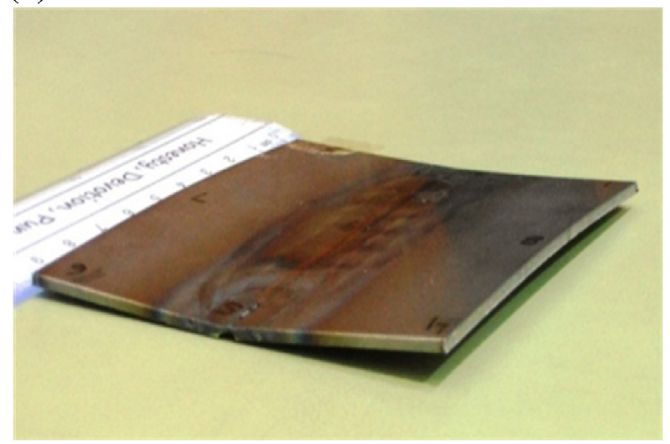

(b)

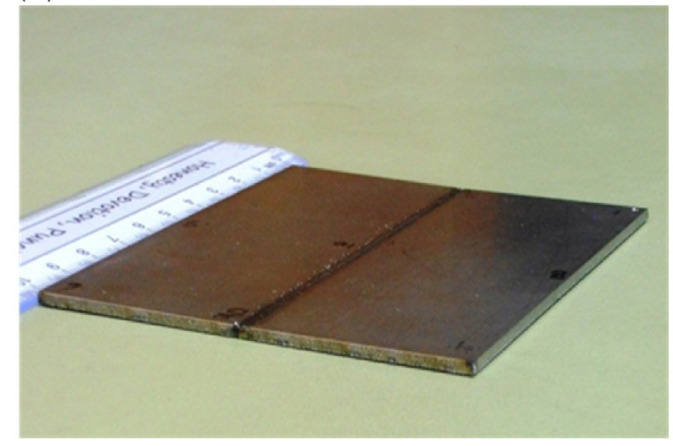

Fig. 16. Distortion pattern in (a) P-TIG and (b) P-LBW weldments.

$\beta$ grains in FZ and HAZ led to a slight decrease in elongation at fracture in P-TIG weldment.

- In order to achieve full penetration in welding $1.6 \mathrm{~mm}$ thin sheet of Ti-5Al-2.5Sn, P-TIG welding resulted in a maximum tensile residual stress of about $430 \mathrm{MPa}$ at a distance of $3 \mathrm{~mm}$ from weld center line and at a depth of about $0.4 \mathrm{~mm}$ from surface. P-LBW resulted in compressive stress of about $100 \mathrm{MPa}$ at $3 \mathrm{~mm}$ from weld center line and at a depth of $0.8 \mathrm{~mm}$ from the surface.

- The generation of a wider HAZ in P-TIG welding resulted in a greater spread of tensile residual stresses until about $18 \mathrm{~mm}$ from weld center line, while narrower P-LBW shifted the tensile residual stresses to compressive at less than $3 \mathrm{~mm}$ from weld center 
(a)

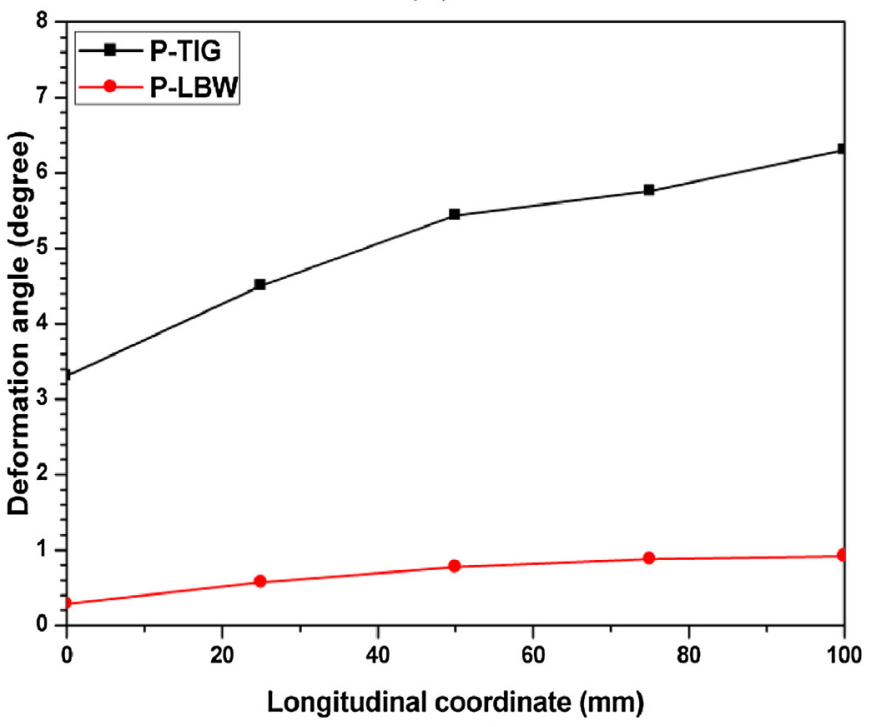

(b)

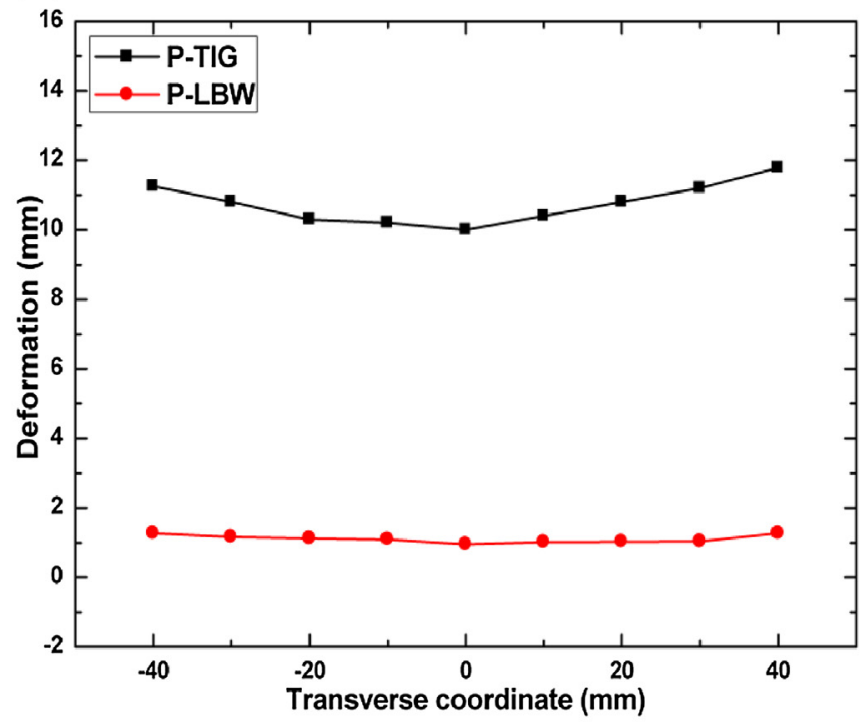

(c)

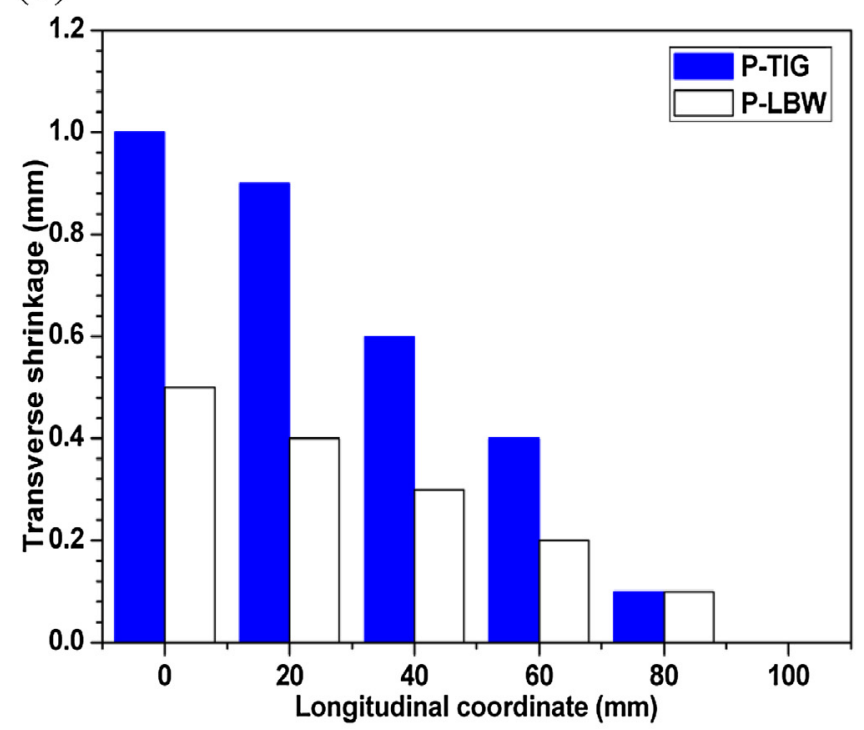

Fig. 17. (a) Angular deformation (b) deformation along transverse direction and (c) transverse shrinkage.

line. The difference between top and bottom width of FZ can be related to trend of non-uniformity in through thickness stress profile. Since the top to bottom width ratio is greater for P-LBW, it has more non-uniformity in through thickness stress profile as compared to P-TIG weldment.

- Compared to P-TIG welding, P-LBW resulted in a narrower width of HAZ and FZ, less deformation, transverse shrinkage and angular distortion. Angular distortion increased towards the extinguishing end of plate for both P-LBW and P-TIG welds.

- In general, P-LBW is more feasible for welding thin sheets of Ti5Al-2.5Sn alloy because of less distortion and reduced residual stresses as compared to P-TIG welding.

\section{Acknowledgments}

The authors would like to thank Ghulam Ishaq Khan Institute of Engineering Sciences and Technology (GIKI) for providing financial assistance and Pakistan Welding Institute (PWI) and Pakistan Institute of Engineering and Applied Sciences (PIEAS) for use of facilities.

\section{References}

ASTM International, 2003. Standard test method for determining residual stresses by the hole-drilling strain. In: ASTM Standard E837-13a. ASTM International, West Conshohocken, PA.

Ahmed, T., Rack, H.J., 1998. Phase transformations during cooling in $\alpha+\beta$ titanium alloys. Mater. Sci. Eng. A 243, 206-211.

Akman, E., Demir, A., Canel, T., Sinmazçelik, T., 2009. Laser welding of Ti6Al4V titanium alloys. J. Mater. Process. Technol. 209, 3705-3713.

Appolaire, B., Settefrati, A., Aeby-Gautier, E., 2015. Stress and strain fields associated with the formation of $\alpha$ in near- $\beta$ titanium alloys. Mater. Today: Proc. 2-3, S589-S592.

Babu, N.K., Sundara, S.G., Mythili, R., Saroja, S., 2007. Correlation of microstructure with mechanical properties of TIG weldments of Ti-6Al-4V made with and without current pulsing. Mater. Charact. 58, 581-587.

Balasubramanian, T.S., Balakrishnan, M., Balasubramanian, V., Manickam, M.A., 2011. Influence of welding processes on microstructure, tensile and impact properties of Ti-6Al-4 V alloy joints. Trans. Nonferrous Met. Soc. China 21, 1253-1262 (English Ed.).

Barroso, A., Cañas, J., Picón, R., París, F., Méndez, C., Unanue, I., 2010. Prediction of welding residual stresses and displacements by simplified models. Experimental validation. Mater. Des. 31, 1338-1349.

Blackburn, J.E., Allen, C.M., Hilton, P.A., Li, L., Hoque, M.I., Khan, A.H., 2010. Modulated Nd:YAG laser welding of Ti-6Al-4V. Sci. Technol. Weld. Join. 15, 433-439. 
Brien, O., William, R., 2007. Predicting Weld Distortion in the Design of Automotive Components. MS Thesis. Durham University, School of Engineering.

Cao, X., Jahazi, M., 2009. Effect of welding speed on butt joint quality of Ti-6Al-4V alloy welded using a high-power Nd:YAG laser. Opt. Lasers Eng. 47, 1231-1241.

Chuan, L., Jianxun, Z., Jing, N., 2009. Numerical and experimental analysis of residual stresses in full-penetration laser beam welding of Ti6Al4V alloy. Rare Met. Mater. Eng. 38, 1317-1320.

Commin, L., Dumont, M., Rotinat, R., Pierron, F., Masse, J.E., Barrallier, L., 2012 Influence of the microstructural changes and induced residual stresses on tensile properties of wrought magnesium alloy friction stir welds. Mater. Sci. Eng. A 551, 288-292.

Deng, D., Murakawa, H., 2008. Prediction of welding distortion and residual stress in a thin plate butt-welded joint. Comput. Mater. Sci. 43, 353-365.

Elmer, J.W., Palmer, T.A., Babu, S.S., Zhang, W., DebRoy, T., 2004. Phase transformation dynamics during welding of Ti-6Al-4V. J. Appl. Phys. 95 8327-8337.

Ferro, P., Berto, F., James, M.N., 2016. Asymptotic residual stresses in butt-welded joints under fatigue loading. Theor. Appl. Fract. Mech. 83, 114-124.

Firm, K., Boyer, R., Welsch, G., 1994. Materials Properties Handbook: Titanium Alloys. ASM International, Materials Park, $\mathrm{OH}$.

Flaman, M.T., 1985. Comparison of four hole-producing techniques for the center-hole residual-stress measurement method. Exp. Tech. 9, 30-32.

Gao, X.-L., Zhang, L.-J., Liu, J., Zhang, J.-X., 2013. A comparative study of pulsed Nd:YAG laser welding and TIG welding of thin Ti6Al4V titanium alloy plate. Mater. Sci. Eng. A 559, 14-21.

Ghaini, F.M., Hamedi, M.J., Torkamany, M.J., Sabbaghzadeh, J., 2007. Weld metal microstructural characteristics in pulsed Nd:YAG laser welding. Scr. Mater. 955-958.

Goldak, J.A., Akhlaghi, M., 2005. Computational Welding Mechanics. Springer Science \& Business Media, New York, pp. 1-321.

Grant, P., V, Lord, J.D., Whitehead, P., 2006. The Measurement of Residual Stresses by the Incremental Hole Drilling Technique - Issue 2. Meas. Good Pract. Guid. No 53.

Huang, H., Wang, J., Li, L., Ma, N., 2016. Prediction of laser welding induced deformation in thin sheets by efficient numerical modeling. J. Mater. Process. Technol. 227, 117-128.

Karpagaraj, A., Siva Shanmugam, N., Sankaranarayanasamy, K., 2015. Some studies on mechanical properties and microstructural characterization of automated TIG welding of thin commercially pure titanium sheets. Mater. Sci. Eng. A 640 180-189.

Kohandehghan, A.R., Serajzadeh, S., Kokabi, A.H., 2010. A study on residual stresses in gas tungsten arc welding of AA5251. Mater. Manuf. Process. 25, 1242-1250.

Lathabai, S., Jarvis, B.L., Barton, K.J., 2001. Comparison of keyhole and conventional gas tungsten arc welds in commercially pure titanium. Mater. Sci. Eng. A 299, 81-93.

Lee, H.T., Liu, C., 2009. Optimizing the EDM hole-drilling strain gauge method for the measurement of residual stress. J. Mater. Process. Technol. 209, 5626-5635.

Leggatt, R.H., 2008. Residual stresses in welded structures. Int. J. Press. Vesseles. Pip. 85, 144-151.

Leyens, C., Peters, M., 2003. Titanium and Titanium Alloys. Wiley-VCH Verlag GmbH \& Co. KGaA, Weinheim, FRG.

Liu, H., Nakata, K., Yamamoto, N., Liao, J., 2011a. Mechanical properties and strengthening mechanisms in laser beam welds of pure titanium. Sci. Technol. Weld. Join. 16, 581-585.

Liu, H., Nakata, K., Zhang, J.X., Yamamoto, N., Liao, J., 2011b. Microstructural evolution of fusion zone in laser beam welds of pure titanium. Mater. Charact. $65,1-7$.

Long, H., Gery, D., Carlier, A., Maropoulos, P.G., 2009. Prediction of welding distortion in butt joint of thin plates. Mater. Des. 30, 4126-4135.

Luo, Y., Murakawa, H., Ueda, Y., 1997. Prediction of welding deformation and residual stress by elastic FEM based on inherent strain. Second report: deformation and residual stress under multiple thermal cycles. J. Soc. Nav. Archit Jpn. 182, 783-793.
Ma, N., Huang, H., Murakawa, H., 2015. Effect of jig constraint position and pitch on welding deformation. J. Mater. Process. Technol. 221, 154-162.

Mehdi, B., Badji, R., Ji, V., Allili, B., Bradai, D., Deschaux-Beaume, F., Soulié, F., 2016. Microstructure and residual stresses in Ti-6Al-4V alloy pulsed and unpulsed TIG welds. J. Mater. Process. Technol. 231, 441-448.

Mi, G., Wei, Y., Zhan, X., Gu, C., Yu, F., 2014. A coupled thermal and metallurgical model for welding simulation of Ti-6Al-4V alloy. J. Mater. Process. Technol. $214,2434-2443$.

Murakawa, H., 2013. 13-Residual stress and distortion in laser welding: Woodhead Publ. Ser. Electron. Opt. Mater. 2, 374-400.

Murugan, S., Rai, S.K., Kumar, P.V., Jayakumar, T., Raj, B., Bose, M.S.C., 2001 Temperature distribution and residual stresses due to multipass welding in type 304 stainless steel and low carbon steel weld pads. Int. J. Press. Vessel. Pip. 78, 307-317.

Nasim, K., Arif, A.F.M., Al-Nassar, Y.N., Anis, M., 2015. Investigation of residual stress development in spiral welded pipe. J. Mater. Process. Technol. 215, 225-238.

Pasang, T., Sánchez Amaya, J.M., Tao, Y., Amaya-Vazquez, M.R., Botana, F.J., Sabol J.C., Misiolek, W.Z., Kamiya, O., 2013. Comparison of Ti-5Al-5V-5Mo-3Cr welds performed by laser beam, electron beam and gas tungsten arc welding. Procedia Eng. 63, 397-404.

Ravisankar, A., Velaga, S.K., Rajput, G., Venugopal, S., 2014. Influence of welding speed and power on residual stress during gas tungsten arc welding (GTAW) of thin sections with constant heat input: a study using numerical simulation and experimental validation. J. Manuf. Process. 16, 200-211.

Rendler, N.J., Vigness, I., 1966. Hole-drilling strain-gage method of measuring residual stresses. Exp. Mech. 6, 577-586.

Rossini, N.S., Dassisti, M., Benyounis, K.Y., Olabi, A.G., 2012. Methods of measuring residual stresses in components. Mater. Des. 35, 572-588.

Schajer, G.S., 1981. Application of finite element calculations to residual stress measurements. J. Eng. Mater. Technol. 103, 157-163.

Short, A.B., 2009. Gas tungsten arc welding of $\alpha+\beta$ titanium alloys: a review. Mater. Sci. Technol. 25, 309-324.

Squillace, A., Prisco, U., Ciliberto, S., Astarita, A., 2012. Effect of welding parameters on morphology and mechanical properties of Ti-6Al-4V laser beam welded butt joints. J. Mater. Process. Technol. 212, 427-436.

Sridhar, B.R., Devananda, G., Ramachandra, K., Bhat, R., 2003. Effect of machining parameters and heat treatment on the residual stress distribution in titanium alloy IMI-834. J. Mater. Process. Technol. 139, 628-634.

Sun, Z., Annergren, I., Pan, D., Mai, T., 2003. Effect of laser surface remelting on the corrosion behavior of commercially pure titanium sheet. Mater. Sci. Eng. A 345, 293-300.

Sundaresan, S., Janaki Ram, G.D., Madhusudhan Reddy, G., 1999. Microstructural refinement of weld fusion zones in $\alpha-\beta$ titanium alloys using pulsed current welding. Mater. Sci. Eng. A. 262, 88-100.

Taljat, B., Radhakrishnan, B., Zacharia, T., 1998. Numerical analysis of GTA welding process with emphasis on post-solidification phase transformation effects on residual stresses. Mater. Sci. Eng. A. 246, 45-54.

Vander Voort, George F., 2004. Metallography and Microstructures, vol. 9. ASM International.

Wang, S., Wu, X., 2012. Investigation on the microstructure and mechanical properties of Ti-6Al-4V alloy joints with electron beam welding. Mater. Des. 36, 663-670.

Zeng, L., Bieler, T.R., 2005. Effects of working, heat treatment, and aging on microstructural evolution and crystallographic texture of $\alpha, \alpha^{\prime}, \alpha^{\prime \prime}$ and $\beta$ phases in Ti-6Al-4V wire. Mater. Sci. Eng. A 392, 403-414.

Zhang, J.X., Xue, Y., Gong, S.L., 2005. Residual welding stresses in laser beam and tungsten inert gas weldments of titanium alloy. Sci. Technol. Weld. Join. 10, 643-646.

Zhang, J., Bin Fan, D., Sun, Y.N., Zheng, Y.F., 2007. Microstructure and hardness of the laser surface treated titanium. Key Eng. Mater. 353-358, 1745-1748. 